University of Louisville

ThinkIR: The University of Louisville's Institutional Repository

Electronic Theses and Dissertations

$8-2020$

\title{
Differences in opportunity evaluation between corporate and independent entrepreneurs.
}

\author{
Alireza Aghaey \\ University of Louisville
}

Follow this and additional works at: https://ir.library.louisville.edu/etd

Part of the Entrepreneurial and Small Business Operations Commons

\section{Recommended Citation}

Aghaey, Alireza, "Differences in opportunity evaluation between corporate and independent entrepreneurs." (2020). Electronic Theses and Dissertations. Paper 3579.

https://doi.org/10.18297/etd/3579

This Doctoral Dissertation is brought to you for free and open access by ThinkIR: The University of Louisville's Institutional Repository. It has been accepted for inclusion in Electronic Theses and Dissertations by an authorized administrator of ThinkIR: The University of Louisville's Institutional Repository. This title appears here courtesy of the author, who has retained all other copyrights. For more information, please contact thinkir@louisville.edu. 
DIFFERENCES IN OPPORTUNTIY EVALUATION BETWEEN CORPORATE AND INDEPENDENT ENTREPRENEURS

\author{
By \\ Alireza Aghaey \\ B.S., Sharif University of Technology, 2007 \\ M.B.A, University of Economic Sciences, 2014
}

\author{
A Dissertation \\ Submitted to the Faculty of the \\ College of Business of the University of Louisville \\ in Partial Fulfillment of the Requirements \\ for the Degree of \\ Doctor of Philosophy \\ in Entrepreneurship \\ Department of Entrepreneurship \\ University of Louisville \\ Louisville, Kentucky
}

August 2020 
Copyright 2020 by Alireza Aghaey

All rights reserved 

DIFFERENCES IN OPPORTUNTIY EVALUATION BETWEEN CORPORATE AND INDEPENDENT ENTREPRENEURS

\author{
By \\ Alireza Aghaey \\ B.S., Sharif University of Technology, 2007 \\ M.B.A., University of Economic Sciences, 2014
}

A Dissertation Approved on

April 29, 2020

by the following Dissertation Committee

Dr. Robert P. Garrett

Dr. James O. Fiet

Dr. Michael J. Barone

Dr. Dean A. Shepherd 


\section{DEDICATION}

To my parents,

For their love, encouragement, and support throughout my life

To my wife,

For her love and understanding and for helping me achieve my goals

\&

To our daughter, Eva,

Who is a blessing from above 


\section{ACKNOWLEDGEMENTS}

I would like to sincerely thank my dissertation chair, Dr. Robert Garrett, for being a great mentor and for providing his support, expertise, and resources wholeheartedly throughout the dissertation process. I would also like to express my gratitude to my other committee members, Dr. Fiet, Dr. Barone, and Dr. Shepherd, for generously offering their support and guidance in improving the quality of this dissertation. 


\title{
ABSTRACT \\ DIFFERENCES IN OPPORTUNTIY EVALUATION BETWEEN CORPORATE AND INDEPENDENT ENTREPRENEURS
}

\begin{abstract}
Alireza Aghaey
April 29, 2020

Opportunity evaluation is a critical step in the process of entrepreneurship and is the main precursor to entrepreneurial action. This is true for both corporate entrepreneurs and independent entrepreneurs. However, these two groups may evaluate entrepreneurial opportunities in different ways because they operate in different contexts and have different decision-making schemas. In my dissertation, I use an "entrepreneurial cognition" perspective to explore such differences. By using two major theoretical lenses - i.e. resource availability and tolerance for uncertainty - and employing a conjoint experimental design, I compare and contrast decision policies of corporate and independent entrepreneurs captured in real time. Also, with reference to social cognitive theory, I account for the effect of individual differences and environmental conditions on opportunity assessments.
\end{abstract}

The findings of this dissertation shed light on differing cognitions of entrepreneurs in corporate and non-corporate contexts and explain their decision-making priorities and tradeoffs. Findings provide evidence that the four opportunity attributes studies - i.e. knowledge of customer demand, resource-relatedness, novelty, and entry scale - 
significantly affect willingness of entrepreneurs to pursue opportunities, but that the effect for all attributes is stronger among independent entrepreneurs. Findings of this study also demonstrate that gender, entrepreneurial experience, and entrepreneurial self-efficacy (as individual characteristics) and industry munificence (as an environmental factor) have significant impacts on opportunity assessments of corporate and independent entrepreneurs, but with varying levels. More detailed discussion of results and implications for research and practice are provided. 


\section{TABLE OF CONTENTS}

ACKNOWLEDGEMENTS ..................................................................................... iv

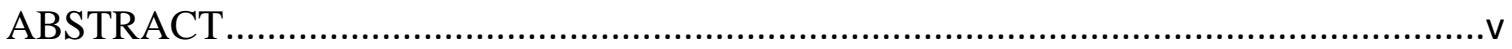

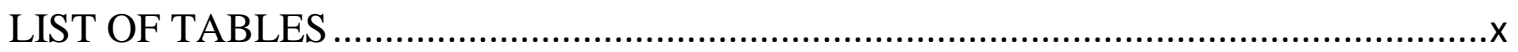

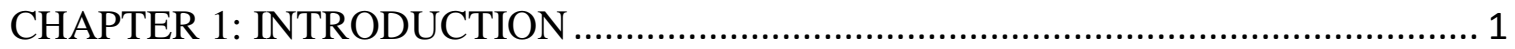

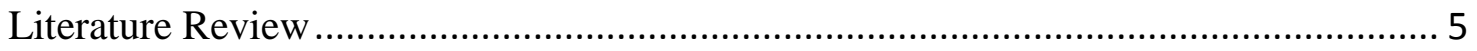

Entrepreneurial Process and Opportunity Evaluation …………………………...... 5

Salient perspectives in opportunity evaluation ........................................................ 7

Shapero's intention-based model ................................................................... 7

Social Cognitive Theory ................................................................................. 7

First-person vs. third-person opportunity.......................................................... 8

Categories of Factors Affecting Opportunity Evaluation......................................... 10

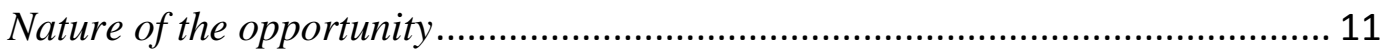

Characteristics of individuals .......................................................................... 11

Environmental conditions ........................................................................... 12

Corporate Entrepreneurship vs. Independent Entrepreneurship............................... 13

Statement of Research Question................................................................................ 17

CHAPTER 2: THEORY DEVELOPMENT AND HYPOTHESES …………………..... 19

Section I: Opportunity Evaluation with Regard to the Nature of the Opportunity ........ 20

Resource-based View (RBV) and Resource Availability.......................................... 20

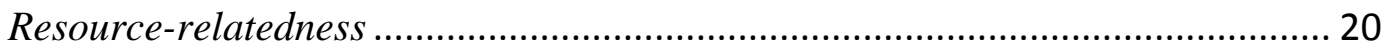

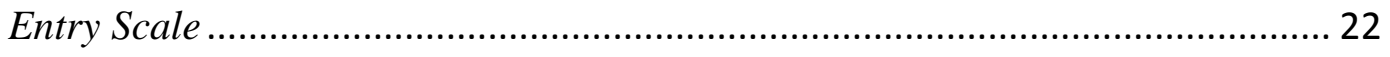

Uncertainty and Entrepreneurial Action................................................................. 23

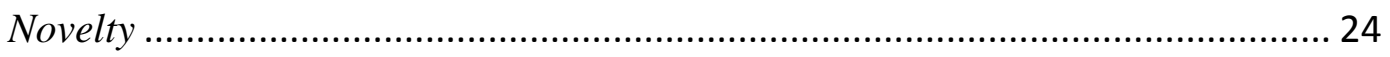

Knowledge of customer demand .................................................................... 26

Section II: Interaction among Opportunity Attributes .................................................. 27 


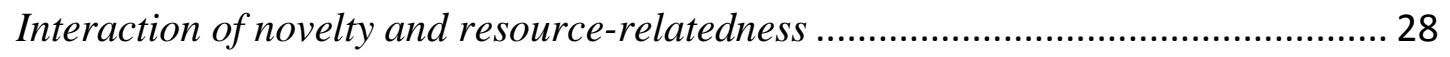

Interaction of novelty and entry scale ................................................................ 29

Interaction of novelty and knowledge of customer demand ..................................... 30

Section III: Interaction of Environmental Conditions and Opportunity Attributes ...... 31

Effect of environmental dynamism on pursuit of a novel opportunity....................... 32

Effect of environmental dynamism on pursuit of a large-scale opportunity .............. 33

Effect of industry munificence on pursuit of a large-scale opportunity ..................... 34

CHAPTER 3: RESEARCH DESIGN AND METHODS............................................... 37

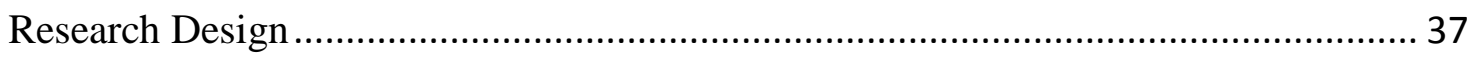

Pre-experiment questionnaire ………………………....................................... 37

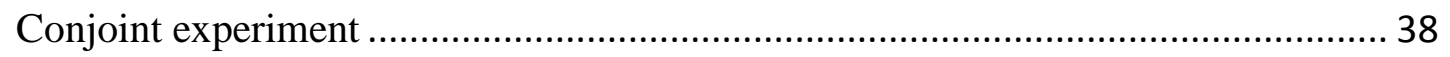

Hierarchical Linear Modeling (HLM) .................................................................. 41

Sample

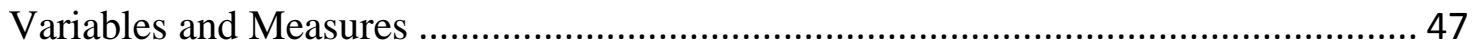

Level 1: Opportunity assessment ........................................................................ 47

Level 2: Perceived environmental dynamism.......................................................... 48

Level 2: Perceived industry munificence. ............................................................... 49

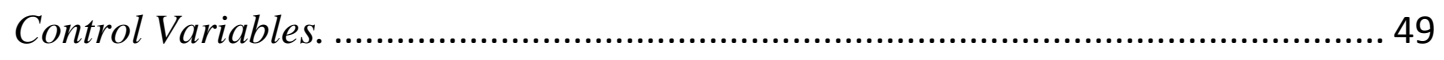

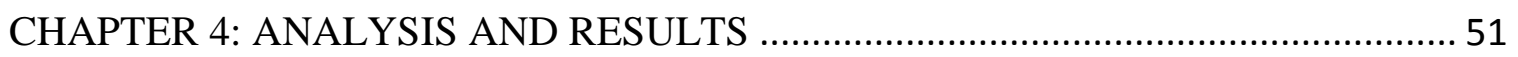

Results for the Hypothesized Relationships............................................................. 51

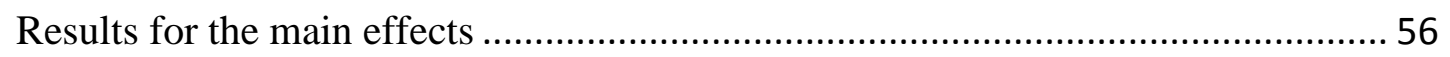

Results for the two-way interactions among predictors .......................................... 58

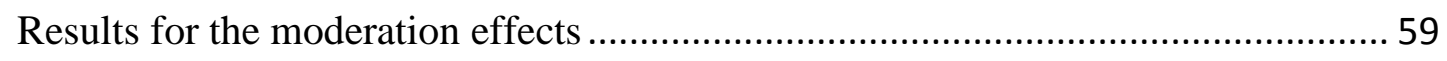

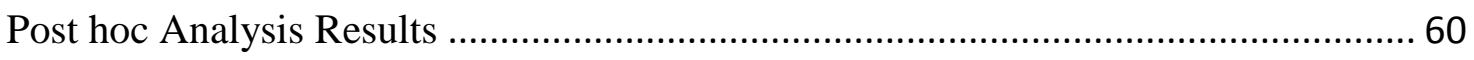

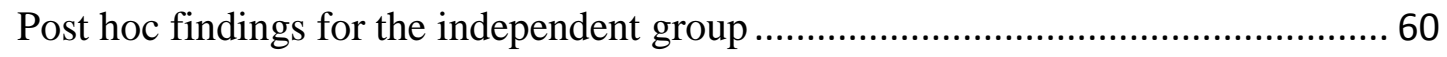

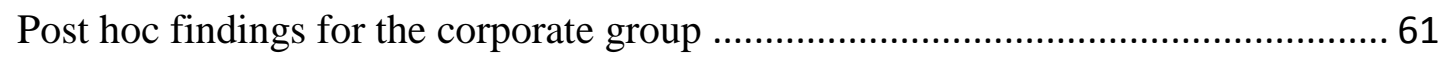

CHAPTER 5: DISCUSSION AND CONCLUSION …………………………........... 63

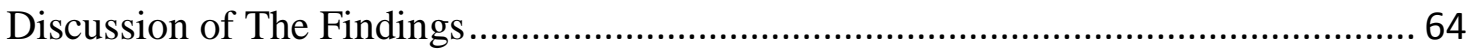

Nature of an opportunity and opportunity attractiveness ........................................ 64

Direct effects of opportunity attributes .............................................................. 65

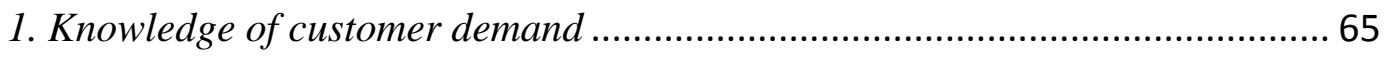




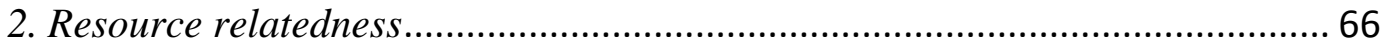

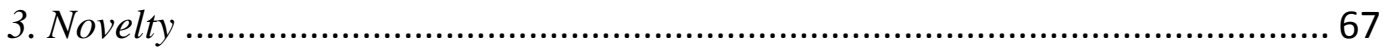

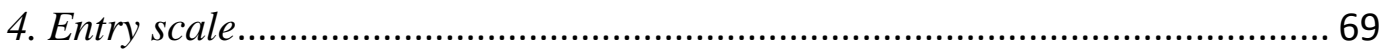

Interaction effects among opportunity attributes.................................................. 70

Individual differences and opportunity attractiveness.............................................. 72

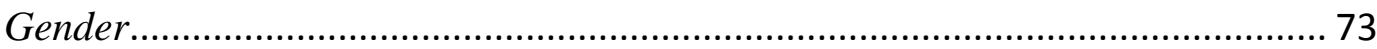

Entrepreneurial experience ……………………….......................................... 74

Entrepreneurial self-efficacy .................................................................... 76

Environmental conditions and opportunity attractiveness......................................... 77

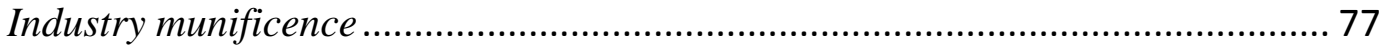

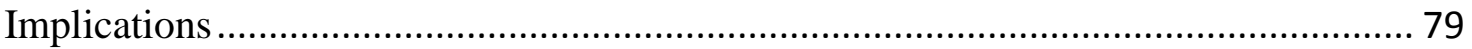

Theoretical implications ………………........................................................ 79

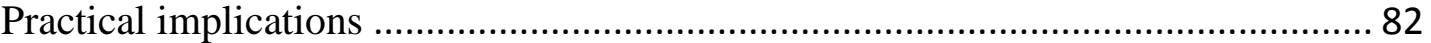

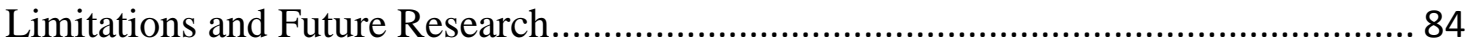

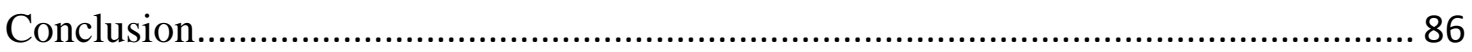

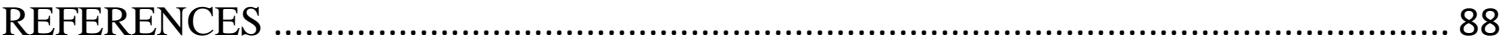

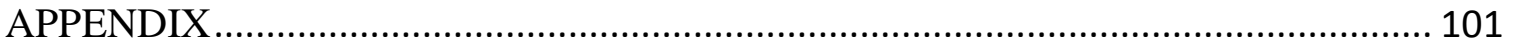

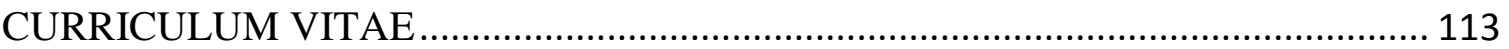




\section{LIST OF TABLES}

TABLE 1: Corporate and Independent Entrepreneurship Contexts ................................. 15

TABLE 2: Descriptive Statistics for the two samples ................................................... 46

TABLE 3: Sample Opportunity Profile ………………................................................. 48

TABLE 4: Means, Standard Deviations, and Correlations for the Independent Sample . 52

TABLE 5: Means, Standard Deviations, and Correlations for the Corporate Sample ..... 52

TABLE 6: Unconditional Model for Independent and Corporate Samples ..................... 53

TABLE 7: Controls-only Model for Independent and Corporate Samples ....................... 54

TABLE 8: HLM Results for the Independent Sample …………………………........... 55

TABLE 9: HLM Results for the Corporate Sample ..................................................... 56

TABLE 10: Opportunity Attribute Preferences ............................................................. 58

TABLE 11: Post hoc results for the Independent Sample ................................................ 61

TABLE 12: Post hoc results for the Corporate Sample .................................................. 62 


\section{CHAPTER 1: INTRODUCTION}

Entrepreneurs make decisions regarding resource allocation and the future value of goods and services under conditions of uncertainty (Casson, 1982; Hébert \& Link, 1988; Knight, 1921). Therefore, decision-making is central to the theory of the entrepreneur. One of the most important decisions an entrepreneur faces is the decision to act upon an entrepreneurial opportunity. Through opportunity evaluation, an entrepreneur assesses the feasibility and desirability of an opportunity and determines if a third-person opportunity (a potentially profitable opportunity) constitutes a first-person opportunity (an actionable opportunity for him/her) (McMullen \& Shepherd, 2006). An entrepreneur will not exploit an opportunity unless he/she believes that the "expected value of the entrepreneurial profit will be large enough to compensate for the opportunity cost of other alternatives [...], the lack of liquidity of the investment of time and money, and a premium for bearing uncertainty" (Shane \& Venkataraman, 2000, p. 223). Previous research pinpoints a myriad

of factors that affect the evaluation of an opportunity by an entrepreneur. A number of these factors include inimitability, complementarity to existing knowledge, limits on competition in the market (Haynie, Shepherd, \& McMullen, 2009), an entrepreneur's emotional state (Grichnik, Smeja, \& Welpe, 2010; Hayton \& Cholakova, 2012), perceived uncertainty, rate of technological change (McKelvie, Haynie, \& Gustavsson, 2011), industry munificence (Shepherd, Patzelt, \& Baron, 2013), 
self-efficacy (Markman, Balkin, \& Baron, 2002; Shepherd et al., 2013), an entrepreneur's learning style (Corbett, 2005), access to social networks (Autio, Dahlander, \& Frederiksen, 2013; Davidsson \& Honig, 2003; De Carolis \& Saparito, 2006), and an entrepreneur's aspiration levels (Lee \& Venkataraman, 2006).

Entrepreneurship is basically performed by either an individual or a corporation. Whereas independent entrepreneurship describes the process whereby an individual or a group of individuals not associated with an existing organization or entity creates a new organization, corporate entrepreneurship refers to the process by which an individual or a group of individuals who are associated with an existing organization or entity creates a new venture or instigates renewal or innovation within the same organization (Sharma \& Chrisman, 2007). Opportunity-related decisions involve more or less similar decisionmaking criteria for independent and corporate entrepreneurs but with different levels of importance and priority owing to differences between the two groups in terms of their cognitive schemas (Corbett \& Hmieleski, 2007), aspiration levels (Lee \& Venkataraman, 2006; Tversky \& Kahneman, 1974), target market selection (Markides \& Geroski, 2004), social networks and resource availability (Corbett \& Hmieleski, 2007; Garrett \& Holland, 2015), risk-taking propensity (Morris, Kuratko, \& Covin, 2010), self-efficacy (Busenitz \& Barney, 1997; Corbett \& Hmieleski, 2007), etc. However, even in this extensive literature, there is still little knowledge on differences in decision-making between independent entrepreneurs and corporate entrepreneurs, especially in terms of how they decide to pursue (or abandon) an opportunity.

In my dissertation, I try to address the question of why and how opportunity evaluation differs between corporate and independent entrepreneurs. In order to delve 
into this question, I use an "entrepreneurial cognition" perspective. According to Mitchell et al. (2002), "entrepreneurial cognitions are the knowledge structures that people use to make assessments, judgments, or decisions involving opportunity evaluation, venture creation, and growth" (p. 97). In other words, entrepreneurial cognition explains the mental frameworks and the thought processes entrepreneurs use to create meaningful connections among opportunity-related cues and to make decisions with regard to initiating new businesses. One of the important factors that can affect the cognition of entrepreneurs with regard to pursuing opportunities is context. Corporate entrepreneurs (who operate within the context of a large, established firm) and independent entrepreneurs/entrepreneurs have different cognitive schema which result in different cognitions toward opportunities (Corbett \& Hmieleski, 2007). I compare opportunity-related decision-making between corporate and independent entrepreneurs with regard to two perspectives that may explain a great amount of variance in opportunity assessment between the two groups: 1) Resource Availability and 2) Tolerance for Uncertainty. First, the resource-based view of the firm advocates analyzing firms from the resource side (instead of the product side) and posits that firm-specific resources constitute the basis for sustainable growth and competitive advantage (Barney, 1991; Penrose, 1959; Wernerfelt, 1984). According to this view, entrepreneurs assess the viability and the value-creating potential of an opportunity with regard to their resource endowments. However, corporate entrepreneurs in established firms usually have greater and more diverse human capital, financial, and physical resource endowments than independent entrepreneurs (Bhidé, 2003). This difference in resource availability can result in different assessments of a focal opportunity by corporate and independent entrepreneurs. Second, entrepreneurs have to deal with uncertainty when 
acting upon an opportunity because the outcome of an opportunity can never be fully determined in advance (Amabile, 1997; McMullen \& Shepherd, 2006; Smith \& DeGregorio, 2002). However, corporate managers and independent entrepreneurs have different tolerances for uncertainty because they operate in different contexts and employ different strategies for reducing environmental uncertainty (Busenitz \& Barney, 1997; Corbett \& Hmieleski, 2007). Therefore, it is fruitful to compare opportunity evaluation decisions of corporate and independent entrepreneurs with regard to how they deal with environmental uncertainty.

Past research suggests that three broad categories of factors influence entrepreneurial opportunity evaluation: individual characteristics, nature of the opportunity, and environmental conditions (as inspired by studies such as Choi \& Shepherd, 2004; Corbett, 2005; Dewald \& Bowen, 2010; Dimov, 2010; Haynie, Shepherd, \& McMullen, 2009; Haynie, Shepherd, \& Patzelt, 2012; Krueger \& Dickson, 1994; Markman et al., 2002; McKelvie et al., 2011; Shane \& Venkataraman, 2000; Shepherd et al., 2013; Wood, McKelvie, \& Haynie, 2014). With regard to the nature of an opportunity, I propose that the following four opportunity attributes fit well within the two major theoretical perspectives - i.e. resource availability and tolerance for uncertainty - discussed earlier: 1) resource-relatedness, 2) market entry scale, 3) novelty, and 4) knowledge of customer demand. In relation to the influence of environment, I account for the moderating effect of environmental dynamism and environmental munificence on the decision-making of independent and corporate entrepreneurs. As two influential characteristics of entrepreneurs, self-efficacy and regulatory focus are the two major individual-level control variables. 


\section{Literature Review}

\section{Entrepreneurial Process and Opportunity Evaluation}

There exists a variety of definitions for entrepreneurship. Cantillon's (1755) early work implies entrepreneurship is undertaking a business and assuming the risks associated. Gartner (1988), Lumpkin and Dess (1996), and Low and MacMillan (1988) equate entrepreneurship to creation of a new enterprise. Stevenson and Jarillo-Mossi (1986) define entrepreneurship as the process through which individuals pursue profitable opportunities independent of the resources under their control. Schumpeter (1934) believes that entrepreneurship takes place through "creative destruction" when individuals with innovative skills create "technologically superior products and displace incumbent firms" (Tripsas, 1997, p. 119). Casson (1982) also believes that coordination of scarce resources when facing environmental uncertainty is the very essence of entrepreneurship.

In this research, I use a definition of entrepreneurship proposed by Shane and Venkataraman (2000) which also has been widely used in recent scholarly work in the entrepreneurship field. They define entrepreneurship as "the scholarly examination of how, by whom, and with what effects opportunities to create future goods and services are discovered, evaluated, and exploited" (Shane \& Venkataraman, 2000, p. 218). Therefore, opportunity discovery, opportunity evaluation, and opportunity exploitation can be considered the three major building blocks of entrepreneurship and venture creation process (Choi \& Shepherd, 2004). An opportunity discovery takes place when an entrepreneur "makes the conjecture that a set of resources is not put to its best use" (Shane \& Venkataraman, 2000, p. 220). According to Shane and Venkataraman, two broad categories of factors affect the discovery of entrepreneurial opportunities: prior knowledge 
and cognitive properties of individuals. People possess different stocks of information, which differentially affect their ability to recognize opportunities to make profit. Prior knowledge of an individual should be complementary with the new information in the market to trigger entrepreneurial conjecture (Gilad, Kaish, \& Loeb, 1987). Moreover, people have different cognitive abilities in combining existing concepts and information into new ideas to visualize new means-ends relationships and discover entrepreneurial opportunities (Shane \& Venkataraman, 2000). As Gaglio and Katz (2001) state, entrepreneurs with an alertness schema are equipped with objective accuracy and are able to apprehend changing environmental cues by using counterfactual thinking and mental simulations and are able to reassess the situation to come up with previously unthought-of means-ends relationships.

Although opportunity discovery is a necessary condition for entrepreneurship, it is only the starting point in the entrepreneurial process and entrepreneurs have to act upon an opportunity to be able to generate above-average profits (Fiet, 1996; Shane \& Venkataraman, 2000). Whether an entrepreneur decides to exploit an opportunity or eventually aborts it depends on his/her overall assessment of the favorability and attractiveness of that opportunity. These attributes of an opportunity are, in turn, influenced by an entrepreneur's expected return from the focal opportunity vis-à-vis the perceived opportunity cost of other alternatives and the costs associated with bearing the uncertainty (Shane \& Venkataraman, 2000). Below, I will discuss two theoretical perspectives in relation to opportunity evaluation that effectively explain how perceptions of feasibility and desirability of an opportunity direct entrepreneurial intentions toward entrepreneurial action. 


\section{Salient perspectives in opportunity evaluation}

\section{Shapero's intention-based model}

This perspective toward entrepreneurial action describes new venture initiation decision based on entrepreneurial intentions. According to Shapero (1975) and Shapero and Sokol (1982), two conditions are necessary for initiating a new venture. First, an entrepreneur must believe that starting the new venture constitutes a credible action. They further explain that a perception of credibility is contingent upon a belief in feasibility and desirability of an opportunity and a propensity to act. Shapero defines perceived desirability as the degree to which starting a new venture is attractive to an individual, and defines perceived feasibility as the degree to which an individual believes that he/she is personally capable of successfully starting a new business (Krueger, 1993). Second, Shapero holds that new-venture creation requires a precipitating (i.e. triggering) event in the external environment. Taken together, Shapero's intention-based model of entrepreneurial action describes opportunity feasibility and opportunity desirability as the key drivers of entrepreneurial action while acknowledging the triggering role of the external environment.

\section{Social Cognitive Theory}

Social cognitive theory proposes a framework for understanding human behavior and action (Figure 1). According to this theory, 1) behavior, 2) cognitive and other individual-level characteristics, and 3) the external environment have reciprocal interactions and these interactions determine the psychological functioning of an individual with regard to a specific activity (Wood \& Bandura, 1989). This theory implies that individual behavior should be studied in conjunction with personal dispositions and 
environmental factors. According to Taylor (1998), "social psychologists agree that individual behavior is strongly influenced by the environment, especially the social environment; the person does not function in an individualistic vacuum, but in a social context that influences thought, feeling, and action" (p. 3). As applies to the context of this study, entrepreneurial cognition and behavior cannot be fully understood in a vacuum and individual dispositions, as well as environmental conditions (such as dynamism and munificence), play an important role in shaping entrepreneurial behavior and action. Therefore, social cognitive theory provides a suitable framework for understanding intricacies in decision-making of entrepreneurs vis-à-vis the reciprocal relationships among dispositional, behavioral, and environmental factors (Hmieleski \& Baron, 2009; Mitchell et al., 2002).

FIGURE 1: Social Cognition (Bandura, 1986)

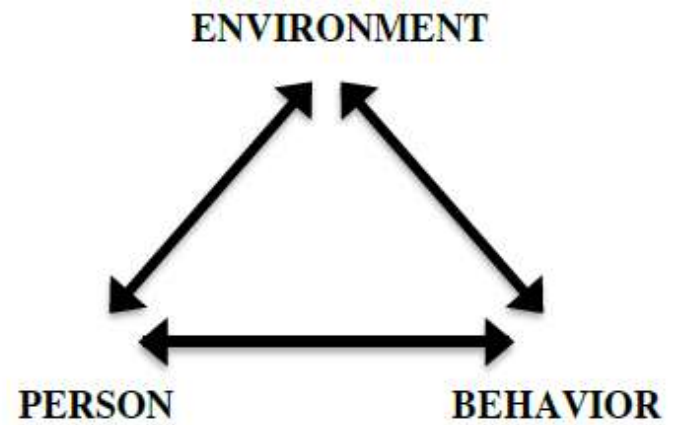

\section{First-person vs. third-person opportunity}

Another salient perspective on opportunity evaluation brings to attention the distinction between a first-person and a third-person opportunity. According to McMullen and Shepherd (2006), decision-making is a necessary but not a sufficient condition for entrepreneurship to take place. Although entrepreneurs make judgements in the face of 
uncertainty, the ultimate entrepreneurial action occurs in the form of a behavior in response to the judgment made to pursue a profitable opportunity (Hébert \& Link, 1988). In line with this notion, McMullen and Shepherd have differentiated between a first-person opportunity and a third-person opportunity. In their delineation, a third-person opportunity refers to a potentially profitable opportunity which is available to the people with the right qualities - i.e. relevant knowledge of time and space (Hayek, 1945). These individuals, as opposed to the average people, possess a knowledge base which is applicable to identification and exploitation of a focal opportunity (McMullen \& Shepherd, 2006). This relevant knowledge reduces the amount of perceived uncertainty by providing these individuals with cues to realize the existence of a profitable opportunity. However, the reduced amount of uncertainty does not guarantee entrepreneurial action because an entrepreneur must also be willing to bear the existing uncertainty and still has to evaluate if the potential reward associated with exploiting the third-person opportunity is greater than the potential cost specific to him/her. If an entrepreneur ultimately believes that the payoff of the third-person opportunity is greater than the costs associated with bearing the uncertainty inherent to that opportunity, a first-person opportunity is deemed to exist and entrepreneurial action occurs (McMullen \& Shepherd, 2006). In this sense, opportunity evaluation acts as a potential bridge between a third-person and a first-person opportunity where a positive evaluation results in exploiting the focal opportunity and a negative evaluation results in abandoning the focal opportunity. McMullen and Shepherd also discuss that whether this risk/return analysis results in a positive or a negative evaluation of a third-person opportunity is subjectively determined by a prospective entrepreneur and 
depends on an individual's situation-specific motivation vis-à-vis the individual's perceived uncertainty in pursuit of the opportunity.

\section{Categories of Factors Affecting Opportunity Evaluation}

According to the above perspectives, opportunity evaluation is a critical step in the entrepreneurial process and is the main precursor to entrepreneurial action. Although initial recognition of a profitable opportunity is the necessary condition for an entrepreneurial action to take place, many new venture ideas do not culminate in new venture creation because an entrepreneur might discard an opportunity whose potential reward is deemed to be lower than the potential cost specific to him/her. Therefore, there is a lot of merit in exploring the factors that can influence an entrepreneur's decision to pursue (or abandon) an opportunity. Past research has pinpointed a myriad of factors in this regard. By using Shane and Venkataraman's (2000) bipartite categorization of factors impacting the decision to exploit an opportunity - i.e. nature of an opportunity and characteristics of individuals - and complementing the classification by adding a third category - i.e. environmental conditions - through integrating findings of the relevant studies (such as Choi \& Shepherd, 2004; Corbett, 2005; Dewald \& Bowen, 2010; Dimov, 2010; Haynie, Shepherd, \& McMullen, 2009; Haynie et al., 2012; Krueger \& Dickson, 1994; Markman et al., 2002; McKelvie et al., 2011; Shepherd et al., 2013; Wood et al., 2014), I can classify factors that affect opportunity evaluation into three major categories: 1) nature of the opportunity, 2) characteristics of individuals, and 3) environmental conditions. This categorization is also consistent with the insights from the three opportunity evaluation perspectives discussed earlier. 


\section{Nature of the opportunity}

Factors belonging to this category describe the attributes of an entrepreneurial opportunity over and beyond the effect of individual characteristics and environmental conditions. A number of opportunity attributes explored in previous studies include complementarity to existing knowledge, rarity (Haynie, Shepherd, \& McMullen, 2009; Shepherd et al., 2013), value, inimitability (Shepherd et al., 2013), novelty (Wood \& Williams, 2014), return from new resources (Wood et al., 2014), knowledge of customer demand (Autio et al., 2013; Casson \& Wadeson, 2007), scale of exploitation, and uncertainty (McKelvie et al., 2011). In this research, nature of an opportunity constitutes

the primary criterion based on which an entrepreneur decides to pursue (or abandon) an opportunity. This is because an entrepreneur will evaluate environmental circumstances and his/her ability to implement an opportunity only if he/she finds an interesting feature or value in the opportunity itself. Opportunity attributes studied in this dissertation are novelty, knowledge of customer demand, resource-relatedness, and entry scale.

\section{Characteristics of individuals}

Individual differences explain a great amount of variance in opportunity evaluation and assessment among entrepreneurs. Prior studies have shown that the propensity to pursue an opportunity can be influenced by individual characteristics such as emotional state (Grichnik et al., 2010; Hayton \& Cholakova, 2012), domain-specific expertise (Dimov, 2010; McKelvie et al., 2011), managerial capabilities (Choi \& Shepherd, 2004), self-efficacy (Markman et al., 2002; Shepherd et al., 2013), illusion of control (Keh, Foo, \& Lim, 2002), self-regulation skills (Bryant, 2007), regretful thinking (Markman et al., 2002), entrepreneurial learning style (Corbett, 2005), Optimism (Krueger \& Dickson, 
1994; Neck \& Manz, 1992; Palich \& Bagby, 1995), meta-cognitive ability (Haynie et al., 2012), aspiration levels (Lee \& Venkataraman, 2006), and self-image (Mitchell \& Shepherd, 2010). In this research, I control for the effect of two individual-level characteristics: entrepreneurial self-efficacy and regulatory focus. Perceived self-efficacy reflects an individual's belief in his/her ability to successfully execute a behavior and highly impacts one's perceptions of feasibility of an opportunity (Krueger Jr, Reilly, \& Carsrud, 2000). Entrepreneurial self-efficacy, in turn, refers to one's perceptions of his/her ability to successfully create and manage a new business (Chen, Greene, \& Crick, 1998). Therefore, entrepreneurial self-efficacy can play a central role in new venture creation decisions. Regulatory focus is used to determine the level of cognitive fit - i.e. the match between one's mode of self-regulation and the requirements of context and external environment - in an individual (Hmieleski \& Baron, 2008). This dissertation uses context as a major determinant of decision policies and priorities among entrepreneurs and measuring cognitive fit would allow me to more accurately capture the impact of context on decision-making.

\section{Environmental conditions}

Conditions in the external environment, whether having a constraining effect or a facilitating effect, can have a significant impact on an entrepreneur's decision to pursue an opportunity. A number of external conditions distinguished in the previous studies include technological change (McKelvie et al., 2011), industry munificence (Shepherd et al., 2013), competition in the opportunity space (Hannan \& Freeman, 1984; Haynie, Shepherd, \& McMullen, 2009), age of firm (Haynie, Shepherd, \& McMullen, 2009), appropriability (Baker, Gedajlovic, \& Lubatkin, 2005), industry maturity (Patterson \& Lightman, 1993), 
social networks (Autio et al., 2013; Davidsson \& Honig, 2003; De Carolis \& Saparito, 2006), stakeholder support (Choi \& Shepherd, 2004), institutional effects (Davidsson, Delmar, \& Wiklund, 2006), industry founding and dissolution rates, industry density (Wood et al., 2014), and perceived environmental threat (Dewald \& Bowen, 2010). In this research, I study the moderating effect of environmental dynamism and industry munificence on opportunity evaluations of corporate and independent entrepreneurs. Environmental dynamism addresses the uncertainty, complexity, and speed of change in the external environment (Miller \& Friesen, 1984) and has been known to influence decision making among managers (Goll \& Rasheed, 1997; Hough \& White, 2003) and entrepreneurs (Miller, 1983; Wiklund \& Shepherd, 2003). Industry munificence refers to scarcity or abundance of resources needed for growth of firms in an industry (Aldrich, 2008; Dess \& Beard, 1984). It has been shown that perceived munificence in an industry impacts beliefs about whether a course of action will result in the expected outcome(s) (Covin \& Slevin, 1989; Tsai, MacMillan, \& Low, 1991). Therefore, exploring the moderating effect of these two external conditions provides us a more fine-grained view of opportunity assessment policies of entrepreneurs.

\section{Corporate Entrepreneurship vs. Independent Entrepreneurship}

Entrepreneurial activities are undertaken either independently or within the context of an established organization (Sharma \& Chrisman, 2007). Although entrepreneurship first emerged as an individual-level phenomenon, its scope was expanded to also include firm-level activities at multiple organizational levels that result in increased risk-taking, proactiveness, and innovation (Barringer \& Bluedorn, 1999; Burgelman, 1991; Covin \& Slevin, 1988). Therefore, corporate entrepreneurship can be defined as the entrepreneurial 
behavior exhibited by a medium-sized or a large organization (Morris et al., 2010). Corporate entrepreneurship has been identified as an effective organizational strategy to spur product and process innovation and sustain competitive advantage in the face of technological uncertainty and change (Morris et al., 2010; Zahra, 1991).

Corporate entrepreneurship has two broad dimensions: new business creation and strategic renewal (Guth \& Ginsberg, 1990). Whereas new business creation (also referred to as corporate venturing, organizational entrepreneurship, and intrapreneurship) involves creating a new venture through expanding an organization's operations, strategic renewal is aimed at acquiring a competitive edge in the market by making changes to an organization's strategic approach or acquiring new capabilities (MacMillan, Block, \& Narasimha, 1986; Zahra, 1993, 1996). The focus of this research is on the venturing aspect of corporate entrepreneurship. In this regard, Sharma and Chrisman's (2007) delineation proves to be useful in describing the distinction between corporate venturing and independent entrepreneurship. In their delineation, independent entrepreneurship describes the process whereby an individual or a group of individuals not associated with an existing organization or entity create a new organization, whereas corporate venturing refers to the process by which an individual or a group of individuals who are associated with an existing organization or entity create a new venture.

\section{Similarities and differences between the two types}

There are a lot of similarities between startup entrepreneurship and corporate entrepreneurship. In both instances, an individual, together with a team, develops a unique business idea to create a profitable new product or service. Therefore, individuals from both groups have to be able to identify rewarding opportunities and pursue them. Moreover, 
both types of entrepreneurs aspire to create value for their prospective customers. In terms of dealing with uncertainty, individual entrepreneurs and corporate entrepreneurs both face a lot of ambiguity in the environment and have to have risk-taking propensity and be willing to act upon uncertain business ideas (Morris et al., 2010). Both groups of entrepreneurs also tend to enact opportunities that are complementary to their existing resource base (including their existing knowledge and skills).

However, there exist a number of sharp differences in the ways corporate entrepreneurs and independent entrepreneurs think and act. These differences can be studied under three major categories: risk/reward relationship, uncertainty bearing and entrepreneurial discretion, and resource availability. Table 1 describes these differences.

\section{TABLE 1: Corporate and Independent Entrepreneurship Contexts}

\begin{tabular}{lll}
\hline & Corporate Entrepreneur & Independent Entrepreneur \\
\hline Risk/Reward & $\begin{array}{l}\text { Not personally accountable } \\
\text { for the risks / limited rewards }\end{array}$ & $\begin{array}{l}\text { Assumes all the risk / } \\
\text { potentially high rewards }\end{array}$ \\
$\begin{array}{l}\text { Uncertainty Bearing } \\
\text { and Entrepreneurial } \\
\begin{array}{l}\text { Discretion } \\
\text { Resource Availability }\end{array}\end{array}$ & Low & High \\
\hline
\end{tabular}

First, independent entrepreneurs usually assume all of the risk associated with creating a new venture whereas corporate entrepreneurs are not personally held accountable for the risks incurred and enjoy a safety net (Burgelman, 1991; Morris et al., 2010). However, the potential rewards from an entrepreneurial opportunity are considerably greater for an individual entrepreneur because he/she can realize returns 
through sources other than a salary, such as licensing fees, dividend payments, and stock shares. But a corporate entrepreneur's compensation beyond his/her salary is usually limited to small bonuses and profit shares (Morris et al., 2010). Moreover, an individual entrepreneur enjoys a psychological ownership of the new venture in terms of personally identifying with the idea or concept whereas in a corporate setting, a new idea belongs to the firm as a whole.

Second, the degree of flexibility in venturing new ideas and taking new directions largely differs in corporate entrepreneurship and independent entrepreneurship settings. Whereas corporate entrepreneurs' new venture ideas have to go through several rounds of approval in an organization to get the final go-ahead, startup entrepreneurs experience more flexibility and less bureaucracy in changing/modifying their courses of action and venturing risky paths (Burns \& Stalker, 1961; Corbett \& Hmieleski, 2007; Morris et al., 2010). Entrepreneurs in large organizations usually are under more scrutiny and have a relatively limited scope in their entrepreneurial activities (Burgelman, 1991). Therefore, the structural and contextual differences between a corporate and a startup setting affect the level of discretion and autonomy an entrepreneur can exercise in pursuing a new venture idea.

Third, resource endowments differentially affect the new venture development process among corporate and independent entrepreneurs. Independent entrepreneurs usually face a lot of resource constraints and have to adjust opportunity implementation scale based on the availability of critical resources in the firm. This may eventually lead these entrepreneurs to discard a lot of potentially profitable opportunities. On the contrary, corporate entrepreneurs usually enjoy access to an abundance of resources already 
available to an organization (such as money, human resources, knowledge repositories, extensive network ties, established customer base, distribution channels, and production facilities) and can potentially implement a new venture idea in a greater scale and with a broader scope (Morris et al., 2010). That being said, a corporate entrepreneur's ability to utilize a firm's resources to implement a business idea may be limited by the conservative policies of the top management that are aimed at preserving the existing organizational assets (Corbett \& Hmieleski, 2007).

It should also be stated that entrepreneurship in a large organization usually is not considered as an end in itself and is used as an insurance against environmental turbulences (Corbett \& Hmieleski, 2007). Top managers may sharply limit the extent of corporate entrepreneurship activities in an organization if their business faces little challenge from its competitors and advocate high levels of entrepreneurship if their business is endangered (Burgelman, 1991).

\section{Statement of Research Question}

My primary aspiration in this research is to theorize and empirically test the differences in opportunity evaluation between corporate and independent entrepreneurs. Therefore, the primary research question of this study is as follows:

$R Q$ : Why and how does opportunity evaluation differ between corporate entrepreneurs and independent entrepreneurs?

As I explained earlier, three categories of factors affect opportunity evaluation: individual differences, nature of the opportunity, and external conditions. In order to be able to better inform my primary research question, I will explore opportunity evaluation 
differences between corporate entrepreneurs and independent entrepreneurs with regard to the three categories mentioned. Therefore, my secondary research questions are as follows:

1. Why and how does the nature of an opportunity differentially affect opportunity evaluation among corporate entrepreneurs and independent entrepreneurs?

2. Why and how do individual characteristics differentially affect opportunity evaluation among corporate entrepreneurs and independent entrepreneurs?

3. Why and how do environmental conditions differentially affect opportunity evaluation among corporate entrepreneurs and independent entrepreneurs? 


\section{CHAPTER 2: THEORY DEVELOPMENT AND HYPOTHESES}

In this chapter, I intend to theorize and hypothesize the differences in opportunity evaluation between corporate entrepreneurs and independent entrepreneurs using two major perspectives: resource availability and uncertainty. Prior research bears witness to the salience of these two perspectives in comparing and contrasting decision-making in a startup and in an established firm setting (e.g. Bhidé, 2003; Busenitz \& Barney, 1997; Corbett \& Hmieleski, 2007; Shrader \& Simon, 1997). Whereas corporate entrepreneurs usually have more abundant and diversified resources at their disposal than do independent entrepreneurs, the former are less willing to and less adept at making opportunity-related decisions under high levels of uncertainty than the latter. Hence, it is very rewarding to explore how the strengths and weaknesses of the two groups interact to differentially affect their opportunity evaluation decisions. In the first section of this chapter, I discuss four opportunity attributes - i.e. resource-relatedness, entry scale, novelty, and knowledge of customer demand - that relate to resource availability and uncertainty and develop maineffect hypotheses. In the second section of this chapter, I discuss how the interactions among opportunity characteristics affect opportunity evaluation among corporate and independent entrepreneurs and I develop second-order hypotheses. In the third section of this chapter, I explore the moderating effect of the salient environmental factors on a number of main-effect relationships and develop another set of second-order hypotheses. 


\section{Section I: Opportunity Evaluation with Regard to the Nature of the Opportunity Resource-based View (RBV) and Resource Availability}

According to the resource-based view, a firm can attain and sustain competitive advantage by using the resources and capabilities specific to the firm (Barney, 1991; Penrose, 1959; Wernerfelt, 1984). This is mainly because strategic resources are heterogeneously distributed across firms in an industry and the value-creating strategy implemented by one firm cannot be duplicated by another firm (Barney, 1991). Of course, not all firm resources have the potential for sustained competitive advantage and four resource attributes have been identified as critical in this regard: value, rarity, imperfect imitability, and non-substitutability. A firm resource is valuable when it can help a firm exploit an opportunity or thwart an environmental threat. A firm resource is rare when it is not possessed by a large number of competing firms. A firm resource is called imperfectly imitable when it cannot be easily duplicated or obtained by competing firms. Finally, a firm resource is non-substitutable when there exists no strategically equivalent resource in the market (Barney, 1991).

\section{Resource-relatedness}

As the resource-based view suggests, a firm can seize profitable opportunities in a market if it has an inward focus on its specific value-creating resources (Barney, 1991; Wernerfelt, 1984). In other words, firm-specific resources constitute the benchmark against which the decision to pursue or abandon an opportunity is made. An opportunity has a greater potential to confer upon a firm a sustainable competitive advantage if it is complementary to and supported by the existing resource endowments of the firm. Firm resources can be practically classified into three categories: physical capital resources, 
human capital resources, and organizational capital resources. Physical capital resources include physical technology, machinery and equipment, geographic location, and access to raw material. Human capital resources include the knowledge, training, experience, intelligence, and relationships of the individuals in a firm. Organizational capital resources include control and planning systems, a firm's reporting structure, intra-firm social networks and inter-firm social networks (Barney, 1991). Corporate entrepreneurs and independent entrepreneurs both evaluate the attractiveness of an opportunity based on availability of such resources. However, Independent entrepreneurs are usually resource constrained and have difficulty attaining financial, human capital, and other types of resources, especially in the early stages of firm growth (Baker \& Nelson, 2005; Penrose, 1959). Therefore, an individual entrepreneur's decision to pursue an opportunity is strongly impacted by the extent to which the resources required to exploit the opportunity are complementary to his/her existing resource endowment. On the contrary, corporate entrepreneurs potentially have access to an abundance of physical, human capital, and financial resources available to a large firm (Bhidé, 2003) and can benefit from economies of scale, economies of scope, and a relatively greater market power to pursue a wide range of profitable opportunities. Although bureaucracy and long approval cycles may limit the smooth flow of available organizational resources to entrepreneurial initiatives in a corporation (Morris et al., 2010), corporate entrepreneurs make opportunity-related decisions based on the availability of all organizational resources to their cause. Resource abundance in a corporation provides a large safety net in pursuing entrepreneurial initiatives and makes resource complementarity requirements of a focal opportunity less of 
a stringent factor (as compared with the requirements in a start-up context). According to the above argument, I propose the following hypothesis:

Hypothesis 1: Independent entrepreneurs, relative to corporate entrepreneurs, are more likely to pursue opportunities whose resource relatedness is high rather than low.

\section{Entry Scale}

Entry of a new venture into a market can take place on a wide range of scale. A small-scale entry can be realized through either a customer specialization strategy or a production specialization strategy. Whereas in a production specialization strategy, a firm focuses on a limited geographical market, maintains excess capacity, and implements forward integration, a customer specialization strategy targets a specific group of customers in the market and is directed at producing a specialty product that has limited demand (McDougall, 1989). Conversely, a large-scale entry is realized through an aggressive production and distribution strategy (aimed at penetrating numerous geographical markets) and requires extensive mobilization of resources and large amounts of investment (Fan, 2010; McDougall, 1989). Previous research has shown that a largescale entry is associated with higher levels of survivability and new venture performance (Biggadike, 1989; Cooper, Willard, \& Woo, 1986; Hobson \& Morrison, 1983; MacMillan \& Day, 1987; Miller \& Camp, 1985). Moreover, firms that enter a new market on a fullscale basis (as compared with a sequential product rollout) can better attain a competitive edge in that market and experience higher levels of performance and profitability (Rodríguez-Pinto, Gutiérrez-Cillán, \& Rodríguez-Escudero, 2007). This is partly because through an aggressive entry, a new entrant can faster attain economies of scale and will 
also be able to ward off retaliatory behaviors of incumbents through signaling availability of abundant resources (Fan, 2010). Along the same lines, it has been shown that whereas a large-scale launch of an opportunity requires huge resource commitments, it can make it difficult for competitors to come up with a timely and effective response (Lumpkin, 2014). That said, high levels of firm density in a market can create intense competition, which, in turn, results in extreme resource scarcity. In such conditions, new ventures with limited resource endowments are forced to exploit marginally profitable opportunities and see little prospects of survivability (Carroll \& Hannan, 1989; Min, Kalwani, \& Robinson, 2006). It has been shown that large incumbents in highly concentrated industries can increase the minimum efficient scale of entry to increase the cost of entry for resource-constrained entrepreneurs (Choi \& Phan, 2006). Therefore, start-ups, as opposed to established firms, are generally less willing to pursue an opportunity that necessitates a large-scale entry into a market because the former usually possess limited resource endowments and lack economies of scale and scope.

Hypothesis 2: Independent entrepreneurs, relative to corporate entrepreneurs, are less likely to pursue opportunities for which the minimum efficient scale of market entry is large rather than small.

\section{Uncertainty and Entrepreneurial Action}

Uncertainty can be defined as "the predictability of conditions in the organization's environment" (Miles \& Snow, 1978, p. 195). Uncertainty is inherent to the entrepreneurial action because entrepreneurs act upon profitable opportunities - such as introduction of new products/services or creation of new entities - whose future outcomes are not readily knowable (Amabile, 1997; McMullen \& Shepherd, 2006; Smith \& DeGregorio, 2002). 
According to Knight (1921), decision making in the context of a business involves judgement and estimation rather than logical reasoning and calculation. Judgement can be defined as "the components of the larger decision-making process that are concerned with assessing, estimating, and inferring what events will occur and what the decision-maker's evaluative reactions to those outcomes will be" (Hastie, 2001, p. 657). Because the future is inherently uncertain and an entrepreneur has partial knowledge of the distribution of future outcomes, he/she has to make judgmental decisions regarding allocation of scarce resources to potentially profitable opportunities (Casson, 1982; Hébert \& Link, 1988; Knight, 1921).

\section{Novelty}

All new ventures are considered innovative, at least to some extent, because they introduce a new offering to the market. Whereas some innovations are truly novel and sharply depart from existing offerings, other innovations are piecemeal and incremental and involve only refinements of or improvements to existing combinations (Amason, Shrader, \& Tompson, 2006; Cheah, 1990). According to Baumol (1996), the former can be referred to as initiation whereas the latter can be labeled imitation. Whether a firm chooses the initiation strategy to create totally new combinations and processes or follows the imitation strategy to discover and capitalize on the discrepancies and gaps in the existing knowledge depends on the degree of novelty it aims to introduce to the market (Cheah, 1990). In this regard, novelty refers to the degree to which new products or services introduced to the market differ from those that already exist (Amason et al., 2006) or to the extent to which firms create new knowledge internally (versus using existing knowledge) to introduce new offerings to the market (Garcia \& Calantone, 2002). 
An entrepreneurial opportunity is considered highly novel when it potentially introduces a highly differentiated product or service to the market. On the contrary, a minimally novel opportunity has a very limited potential to offer a unique product or service to the market. Novelty can introduce technological uncertainty into the product development process as a new combination of resources is required (Fleming, 2001). Managers in large organizations can generally use existing patterns, past performance, and historical trends to reduce the amount of uncertainty they face when making a decision (Amason et al., 2006; Busenitz \& Barney, 1997). But these information are seldom available to entrepreneurs in small firms where routines and elaborate procedures usually do not exist (Miller \& Friesen, 1984). However, when facing a highly novel entrepreneurial opportunity, corporate decision makers see little merit in using routine procedures and past performance data because these tools cannot effectively inform the decision to pursue (or abandon) an opportunity whose implementation involves a totally new combination of resources and processes. In such conditions, however, an individual entrepreneur may be more adept at making an appropriate and timely decision because he/she more extensively uses "biases and heuristics" - i.e. cognitive mechanisms and simplifying strategies that make the decision-making task easier and more effective in uncertain and complex conditions (Busenitz \& Barney, 1997).

Another reason a highly novel opportunity might not appeal to a corporate entrepreneur is the anticipated lack of support from top managers and organization stakeholders. Top managers might be reluctant to deviate from the planned, strategic direction of the organization and to make revolutionary changes to strategic organizational processes to support implementation of a novel business idea. Stakeholders might also see 
little merit in organizational resources being invested in opportunities with uncertain returns (Morris et al., 2010). In a startup, however, bureaucratic norms and routines rarely exist and entrepreneurs experience more flexibility and freedom in venturing highly innovative business ideas (Burns \& Stalker, 1961; Corbett \& Hmieleski, 2007). Therefore, I conclude that corporate entrepreneurs, as compared with startup entrepreneurs, are less interested in pursuing and acting upon novel opportunities.

Hypothesis 3: Independent entrepreneurs, relative to corporate entrepreneurs, are more likely to pursue opportunities that are more novel (than less novel).

\section{Knowledge of customer demand}

In developing a new product/service, entrepreneurs are unsure of the true value that would be delivered to the target customers and, ultimately, about the market acceptance of the new offering. Whereas established firms and startups both face a great deal of demand uncertainty when introducing a new product/service to the market, established firms may anticipate a greater consumer demand due to a relatively larger existing customer base and an already established customer loyalty. According to Choi and Shepherd (2004), consumers' knowledge of a firm's market offerings reduces the uncertainty surrounding the purchasing decisions. It has also been shown that an organization's image can greatly impact customers' perception of the organization's products and services and ultimately, customers' buying behavior (Zeithaml \& Bitner, 1996). Established firms, relative to startups, can anticipate at least a decent level of market acceptance for their new offering due to an existing customer base and familiarity with customers' tastes and needs. On the contrary, a startup has yet to attract its first group of customers and this largely depends on the uniqueness of its new offering. Other things being equal, a startup's new offering has 
lower chances of getting adopted by target customers due to customers' relatively lower brand awareness and lack of brand loyalty (Crane, 2012). Therefore, when it comes to evaluating an opportunity, individual entrepreneurs, as opposed to corporate entrepreneurs, are more concerned about demand uncertainty and market acceptance of their new-to-themarket product/service. I conclude that an individual entrepreneur's decision to exploit an opportunity, as opposed to a corporate entrepreneur's decision, is more critically contingent on the prior knowledge of customer demand.

Hypothesis 4: Independent entrepreneurs, relative to corporate entrepreneurs, are more likely to pursue opportunities for which the knowledge of customer demand is high rather than low.

\section{Section II: Interaction among Opportunity Attributes}

In addition to the direct effect an opportunity attribute might have on attractiveness of an opportunity, two opportunity attributes might simultaneously impact an entrepreneur's perceptions of an opportunity. Stated differently, varying levels of one attribute might positively or negatively impact perceptions of another attribute. Among the possible interactions between opportunity attributes, the interaction effect of "novelty" on other attributes appears to be more salient and better explain the variance in decision making between the two types of entrepreneurs. As I stated earlier, implementation of a novel opportunity necessitates a totally new combination of resources while introducing technological uncertainty into the product development process (Fleming, 2001). Whereas entrepreneurs in startups experience huge flexibility and freedom in pursuing breakthrough, innovative business ideas, corporate entrepreneurs are under more scrutiny and might perceive little support from top managers and organizational stakeholders in 
pursuing such opportunities. On the one hand, decision-making routines, widely used in established organizations, are of little value when top management is faced with a novel opportunity that defies predictability. On the other hand, organizational stakeholders might anticipate below-average returns on investments in such projects. Therefore, corporate and independent entrepreneurs approach novel opportunities in hugely different ways and I suggest that this could differentially impact their perceptions of other opportunity attributes as well. Below, I develop hypotheses that explain these differential effects.

\section{Interaction of novelty and resource-relatedness}

I earlier showed that resource complementarity positively impacted an entrepreneur's willingness to engage in a new venture opportunity and that this impact was stronger among independent entrepreneurs. Independent entrepreneurs, as opposed to entrepreneurs in established organizations, usually start out with a limited set of resources and don't benefit from economies of scale and scope. Therefore, their willingness to pursue a new business idea largely depends on the degree of relatedness between the focal opportunity and their existing resource endowments. But what if a resource-related opportunity is also a novel one?

As stated earlier, independent entrepreneurs, relative to corporate entrepreneurs, are more likely to pursue novel opportunities for two reasons. First, implementation of a novel opportunity requires a new combination of resources and processes and involves technological uncertainty (Fleming, 2001). Whereas independent entrepreneurs are more adept at using their biases and heuristics to simplify decision-making under such conditions, corporate managers usually rely on historical trends and past performance data - which are of little help in uncertain situations - to make accurate decisions (Busenitz \& 
Barney, 1997). Second, independent entrepreneurs face fewer bureaucratic norms and routines and experience more flexibility and freedom in venturing highly innovative business ideas (Burns \& Stalker, 1961; Corbett \& Hmieleski, 2007). However, entrepreneurs in large organizations perceive little support from the top management in pursuing breakthrough ideas with hardly predictable outcomes. This hurdle exists largely due to the relatively mechanistic structure of an established firm which is usually encompassed by a culture that stresses reliability and efficiency over flexibility and innovation (Morris et al., 2010).

Overall, I propose that novelty widens the gap between the likelihood of an independent and a corporate entrepreneur to pursue a resource-related opportunity.

Hypothesis 5: The difference in the likelihood of independent and corporate entrepreneurs to pursue a resource-related opportunity is even larger when opportunity novelty is high.

\section{Interaction of novelty and entry scale}

I earlier showed that startup entrepreneurs are less likely than corporate managers to exploit business ideas that necessitate a large-scale entry into the market because individual entrepreneurs are usually more resource-constrained and have to procure a large amount of resources from external sources to realize a big-scale market entry. But would an independent entrepreneur be willing to exploit a novel, breakthrough business idea even when the required scale of market entry is large? Research has shown that individual entrepreneurs are more adept at making efficient opportunity decisions in novel situations because they more extensively use cognitive shortcuts and simplifying decision-making strategies (Busenitz \& Barney, 1997). Moreover, independent entrepreneurs experience 
more flexibility and freedom and less bureaucracy in venturing new business ideas than corporate entrepreneurs (Burns \& Stalker, 1961; Corbett \& Hmieleski, 2007). Although a large-scale entry into a market is not inherently attractive to an individual entrepreneur, the opportunity's high level of novelty may persuade the entrepreneur to pursue an adventurous and risky path with potentially high rewards. I contend that an individual entrepreneur's high aspirations to act on an innovative business idea give him/her extra courage and self-confidence in exploiting a large-scale project.

Hypothesis 6: The difference in the likelihood of independent and corporate entrepreneurs to pursue a large-scale opportunity is smaller when opportunity novelty is high.

\section{Interaction of novelty and knowledge of customer demand}

As I stated earlier, large corporations, relative to startups, possess a larger customer base and can rely on their customers' experience with the existing products (or services) of the firm to anticipate a higher demand for a new offering. On the contrary, there is no precedence in the market for a startup's new product and customer demand solely depends on the superior value the product proposes to the targeted consumers. Therefore, an independent entrepreneur is highly concerned with demand uncertainty when deciding to exploit an opportunity. But would an entrepreneur be willing to act upon a highly novel business idea even when he/she anticipates a great amount of uncertainty over customer demand? The answer could be a yes. Whereas corporate managers are more inclined to protect their current products and services against competition, independent entrepreneurs are more interested in exploiting opportunities that culminate in highly innovative products (Corbett \& Hmieleski, 2007; Shrader \& Simon, 1997). Startups usually lack economies of 
scale, economies of scope, and an existing customer base (Morris et al., 2010) and an effective strategy for a startup to secure the customer demand in a market is to introduce a highly novel and differentiated product that can entice and attract loyal customers of established firms. In other words, an independent entrepreneur may perceive of opportunity novelty as a means to reduce demand uncertainty. Therefore, an independent entrepreneur may be less concerned with uncertainty over customer demand when he/she acts upon a very novel and innovative business idea.

Hypothesis 7: The difference in the likelihood of independent and corporate entrepreneurs to pursue an opportunity with a low knowledge of customer demand is smaller when opportunity novelty is high.

\section{Section III: Interaction of Environmental Conditions and Opportunity Attributes}

In this section, I theorize the differences in opportunity evaluation among corporate and independent entrepreneurs with regard to the moderating effect of two salient environmental conditions: dynamism and munificence. Whereas dynamism addresses the uncertainty, complexity, and speed of change in the external environment (Miller \& Friesen, 1984), munificence refers to the scarcity or abundance of resources critical to the growth of firms in an industry (Aldrich, 2008; Dess \& Beard, 1984). These two external conditions tie in well with the two theoretical lenses used in this dissertation - i.e. resource availability and uncertainty - to explore decision-making among entrepreneurs and intrapreneurs. Out of the possible moderation effects dynamism and munificence can have on evaluations of opportunity attributes, I hypothesize those moderation effects that appear to be theoretically justified and better explain variance in decision-making in corporate and non-corporate contexts. 


\section{Effect of environmental dynamism on pursuit of a novel opportunity}

Dynamic industries are associated with high rates of change in customers' tastes, production methods and technologies, variations in product demands, and unpredictability of actions of competitors (Miller \& Friesen, 1984). Firms operating in dynamic industries have to be able to respond quickly and effectively to changes in technology and have to be more entrepreneurial to be able to come up with new offerings and solutions to outperform their competitors (Combs, Ketchen Jr, Ireland, \& Webb, 2011; Helfat \& Raubitschek, 2000; Lumpkin \& Dess, 2001).

As was stated earlier, entrepreneurship in an established organization is usually not considered as an end in itself and may be used as an insurance against the volatilities in the external environment (Corbett \& Hmieleski, 2007). In other words, top managers may sharply limit the extent of corporate venturing and strategic renewal in an organization if their business is running in a fairly stable environment, but may advocate high levels of entrepreneurship if their survivability is threatened by environmental turbulence (Burgelman, 1991; Morris et al., 2010). I previously showed that a major reason the management of a large corporation might not be willing to invest in a highly novel opportunity is to maintain the existing strategic trajectory of the organization and avoid imposing revolutionary changes on organizational operations and processes. However, when facing a highly dynamic environment, top managers and major stakeholders of a large firm may see it as plausible to relinquish their conservative policies and mobilize organizational resources to capitalize on any profitable opportunity in order to ensure survivability of the firm. In such a situation, even pursuing a very novel opportunity could potentially save the company from being outpaced by its competitors. In other words, 
environmental turbulence moderates the decision of corporate managers to pursue a highly novel opportunity through instigating a sense of urgency in the whole organization. Increased support from top layers of management and expedited administrative procedures will encourage corporate entrepreneurs to take on risky projects and pursue breakthrough business ideas. Therefore, environmental dynamism increases the willingness of corporate entrepreneurs to pursue novel opportunities. On the contrary, this effect does not seem to exist at an equal level for an individual entrepreneur. An individual entrepreneur is less likely to experience the same sense of urgency a corporate entrepreneur does in a dynamic setting because the latter will have a considerably greater amount of physical, human capital, and organizational resources at stake if it cannot survive the intensified competition. According to the above argument, I propose the following hypothesis:

Hypothesis 8: The difference in the likelihood of independent and corporate entrepreneurs to pursue a novel opportunity is smaller when perceived environmental dynamism is high.

\section{Effect of environmental dynamism on pursuit of a large-scale opportunity}

I earlier showed that individual entrepreneurs are less likely than corporate managers to exploit business ideas that necessitate a large-scale entry into the market because the former usually possess limited firm resources and operate in a smaller scale. But how would volatility in the external environment impact the attractiveness of an opportunity whose exploitation necessitates a large-scale entry? Turbulent environments are characterized by rapid changes in customer expectations, intensified competition, high rates of technology obsolescence, and complex regulatory, legal, and ethical standards and liabilities (Morris et al., 2010). In such circumstances, investing in a business idea that 
demands a large-scale market entry constitutes a very risky decision for an independent entrepreneur as he/she has to procure a wide array of external resources, in addition to the resources already at his/her disposal, to exploit an opportunity with a narrower window and a less predictable gain. A large corporation, however, is not as severely impacted by resource requirements of a large-scale entry and, at the same time, has more incentives to act upon an existing opportunity to increase the chances of survival in the face of competition. Therefore, an opportunity with a large entry scale will be even less attractive to a startup entrepreneur when the environment is turbulent and volatile.

Hypothesis 9: The difference in the likelihood of independent and corporate entrepreneurs to pursue a large-scale opportunity is even larger when perceived environmental dynamism is high.

\section{Effect of industry munificence on pursuit of a large-scale opportunity}

In munificent environments, firms can better thwart external threats and create slack resources (Nielsen \& Nielsen, 2013). Moreover, munificent environments can compensate for entrepreneurial decision-making mistakes through greater environmental capacity and increased overall growth (Shepherd et al., 2013). On the contrary, resourcescarce environments hold little capacity for profitable opportunities due to intense competition over a limited set of resources (Aldrich, 2008; Covin \& Slevin, 1989).

As I stated earlier, as the minimum efficient scale of entry increases in a market, the ratio of incoming startups to incoming corporate ventures decreases because the former usually have access to fewer firm resources and operate in a smaller scale, relative to the latter. However, the ratio can become even smaller in a less munificent industry because individual entrepreneurs operating in such an industry, as opposed to corporate 
entrepreneurs, are more adversely affected by resource scarcity. In other words, in exploiting an opportunity that requires a large-scale entry, low levels of perceived industry munificence impact an independent entrepreneur's decision more severely than a corporate entrepreneur's decision.

Hypothesis 10: The difference in the likelihood of independent and corporate entrepreneurs to pursue a large-scale opportunity is even larger when perceived environmental munificence is high. 


\section{FIGURE 2: The Conceptual Model of the Research ${ }^{1}$}

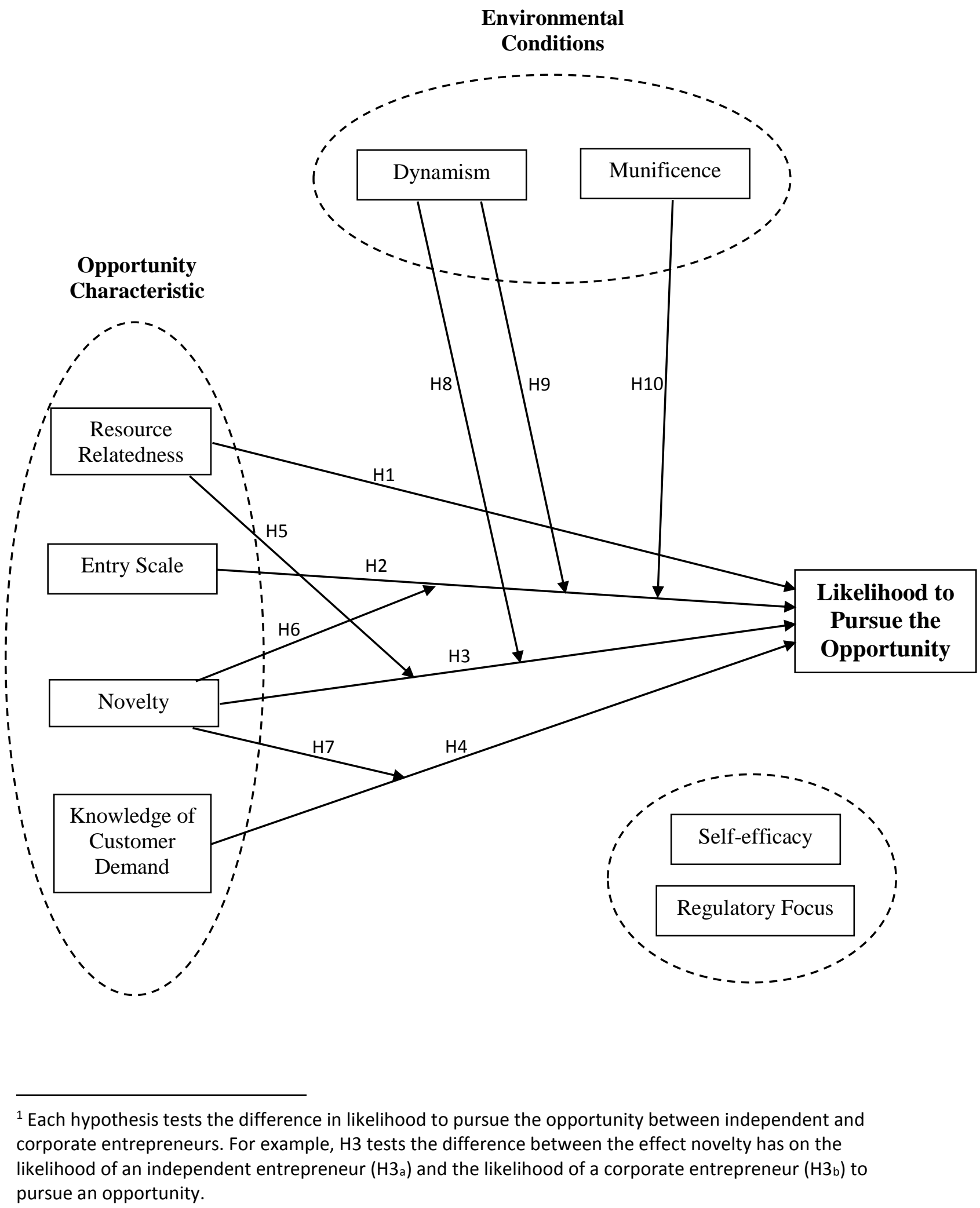




\section{CHAPTER 3: RESEARCH DESIGN AND METHODS}

In this chapter, I explain the detailed design of the study, the analytical techniques used, the sampling process for the research, and the operationalization of the study variables.

\section{Research Design}

The main purpose of this research is to investigate the relative importance of opportunity evaluation criteria that meaningfully explain the variance in decision-making between corporate and independent entrepreneurs. In this regard, I use a conjoint experiment, preceded by a pre-experiment questionnaire, to discover how the nature of an opportunity shapes opportunity evaluation decisions of corporate and independent entrepreneurs vis-à-vis the circumstances in the external environment. Then, I conduct a comparison of the experiment results between corporate entrepreneurs and independent entrepreneurs to explain the differences in opportunity evaluation between the two groups. I also control for individual characteristics of entrepreneurs to partition out their effect on opportunity assessments in the two groups.

\section{Pre-experiment questionnaire}

As discussed in chapters one and two, environmental conditions can impact an entrepreneur's assessment of attractiveness of an opportunity. In this study, environmental 
dynamism and industry munificence have been distinguished as two salient environmental factors that tie in with the theoretical lenses employed in this research - i.e. resource availability and uncertainty. Either a pre-experiment or a post-experiment questionnaire can be used to gauge an entrepreneur's perceived environmental dynamism and industry munificence; however, I chose to have my respondents assess the conditions surrounding their businesses before they engaged in the decision-making task. By drawing entrepreneurs' attention to the enabling (or constraining) forces in the industry first, I can better capture the impact of these forces on opportunity assessments. In other words, by completing a pre-experiment questionnaire, an entrepreneur will potentially make a more realistic assessment of an opportunity as he/she is more likely to recall his/her responses to the questionnaire during the assessment. Therefore, a questionnaire on perceived environmental dynamism and industry munificence preceded the conjoint experiment and was administered to respondents in the beginning of the survey. Respondents were later prompted to evaluate opportunity profiles according to the responses they had provided in this questionnaire.

\section{Conjoint experiment}

I use conjoint experimental design in this research to explore the decision policies of corporate and independent entrepreneurs with regard to pursuing an entrepreneurial opportunity. A conjoint experiment is a "decompositional" research method that estimates the structure of a decision-maker's preferences given his/her overall assessment of a set of alternative decision scenarios. Each decision scenario or profile represents a pre-specified combination of different attribute levels and the output of a conjoint analysis includes the importance weights associated with different attributes (Green \& Srinivasan, 1990). 
Therefore, by conducting a conjoint experiment, a researcher is able to decompose an individual's decision task into the underlying attribute-specific preferences (Shepherd \& Zacharakis, 1997). Conjoint experiments have been used in numerous studies across a variety of disciplines (Green, Krieger, \& Wind, 2001) and are particularly well-suited for investigating complex entrepreneurial decisions (Shepherd et al., 2013). Due to high levels of between-subject variation in decision preferences, a conjoint experiment significantly improves predictive validity by estimating preferences at the individual, rather than at the aggregate, level (Green \& Srinivasan, 1990). Moreover, as a real-time method, conjoint analysis helps mitigate many potential biases associated with post-hoc survey methods (Choi \& Shepherd, 2004). In a conjoint experiment, data is collected from respondents as they make decisions. This effectively minimizes validity threats arising from faulty memory, social desirability concerns, and difficulty in articulating complex decision tasks (Lohrke, Holloway, \& Woolley, 2010; Shepherd \& Zacharakis, 1997).

In this research, I conduct a metric conjoint analysis, which assumes zero correlation between attributes (orthogonality) (Shepherd et al., 2013). Generally, the number of required profiles in a conjoint experiment is determined by the number of attributes, the number of levels at which each attribute varies, and the number of two-way interactions between attributes to be tested. In my study, four attributes related to the nature of an opportunity are the basis for composing the conjoint profiles. These attributes, which were discussed in detail in chapter two, include resource-relatedness, entry scale, novelty, and knowledge of customer demand. Each of these attributes varies at two levels: high and low. Thus, the number of total possible profile combinations is $16\left(2^{4}\right)$. However, only three interactions between the attributes are of interest: interaction between resource- 
relatedness and novelty, interaction between novelty and entry scale, and interaction between novelty and demand uncertainty. Although it is possible to reduce the number of necessary conjoint profiles by using a fraction of all possible attribute combinations (following Hahn \& Shapiro's (1966) orthogonal fractional factorial design), I decide to use a full-profile design to be able to test the significance of any non-hypothesized two-factor interaction in a post hoc analysis. This allows for possible extra theory development on all two-way interaction effects between opportunity attributes, following the preliminary data analysis. Eight conjoint profiles were replicated to allow a comparison between the original profiles and the replicated profiles to test the reliability of the study instrument (also referred to as test-retest reliability analysis) (Haynie, Shepherd, \& McMullen, 2009). Each respondent also evaluated one practice or "warm-up" scenario, which was later dropped from the analysis. Ultimately, each experiment included a total of 25 conjoint profiles. For each conjoint profile, respondents were asked to indicate their willingness to pursue and exploit the presented opportunity. Entrepreneurs indicated their responses along a 9-point Likert scale, with 1 being "very unlikely" and 9 being "very likely".

One of the concerns in a conjoint study is to control for unobservable effects arising from differing contexts in which the respondents evaluate the conjoint scenarios (Shepherd \& Zacharakis, 1997). Therefore, a researcher should try to create a common context for all the respondents to minimize unwanted effects on their assessments. In order to create such a context, I followed a number of steps, partly informed by the study conducted by Haynie et al. (Haynie, Shepherd, \& McMullen, 2009). First, I instructed the respondents that the purpose of my research was to understand the underlying mechanisms and preferences in opportunity evaluation decisions. In this dissertation, opportunity is defined as the potential 
to bring into existence future products/services (Shane \& Venkataraman, 2000). Second, respondents were instructed to evaluate the opportunities in the context of their own business environment and with regard to their evaluations of environmental dynamism and industry munificence in the pre-experiment stage. Third, respondents were told that the focal opportunity was meant to be exploited in the present US business environment. Finally, respondents were asked to evaluate opportunities independent from one another.

\section{Hierarchical Linear Modeling (HLM)}

Because in this study, data is nested within individuals and is analyzed at two levels (i.e. decision making with regard to opportunity attributes and the effect of higher-order variables), I use Hierarchical Linear Modeling (HLM) to conduct a multi-level analysis on the nested data. HLM accounts for potential autocorrelations, allowing independence among observations within an individual (Choi \& Shepherd, 2004). Because each entrepreneur assesses the external environment of his/her business and then evaluates a series of conjoint profiles, there might exist correlations among his/her observations. Intercorrelations among independent variables in a study create disturbance in the data and make the statistical inference unreliable. A hierarchical linear model accounts for the variance among variables at different levels (Woltman, Feldstain, MacKay, \& Rocchi, 2012) and controls for autocorrelation and heteroscedasticity (Shepherd et al., 2013).

Three types of variables exist in an HLM model: outcome variables, predictors (explanatory variables and control variables), and higher-order variables (aggregated variables and contextual variables). The HLM analysis in this research consists of the following models: (1) an unconditional model which tests for intra-class correlation, (2) a random coefficients regression model (level-1 model) which examines the significance of 
predictors (the four attributes of opportunity) and the three two-way interactions hypothesized, and (3) the full model (level-2 model) which adds in environmental moderators as well as the control variables. The analysis was conducted for both groups of entrepreneurs. In order to test for the significance of differences in evaluation between corporate and independent entrepreneurs, attribute weights and interaction terms (which were grand centered in HLM software) were compared across the two datasets using a ztest. The z-score for the difference is calculated using equation 1, provided by Clogg, Petkova, and Haritou (1995):

\section{Equation 1}

$$
Z-\text { score }=\frac{\beta_{1}-\beta_{2}}{\sqrt{\left(S E_{\beta_{1}}{ }^{2}+S E_{\beta_{2}}{ }^{2}\right)}}
$$

Where:

$\beta_{1}=$ Coefficient for group 1

$\beta_{2}=$ Coefficient for group 2

$S E_{\beta_{1}}=$ Standard error for $\beta_{1}$

$S E_{\beta_{2}}=$ Standard error for $\beta_{2}$

\section{Sample}

The sample in this study comprises two major sub-samples: a sample of independent entrepreneurs and a sample of corporate entrepreneurs. Both samples were drawn from three major sources: 1) Executive MBA students and MBA alumni directory of a public university in the mid-western United States, 2) directory of entrepreneurs participating in a local business network, and 3) a third-party data collection company. To 
qualify as an independent entrepreneur in this research, an individual must be a founder and be actively involved in the management of a firm. To qualify as a corporate entrepreneur in this research, an individual should be an employee of an organization with a position fitting in with a broad delineation proposed by Martiarena (2013). According to this definition (which is based on screening questions and business ownership information found in Spanish Global Entrepreneurship Monitor (GEM) database), an intrapreneur/corporate entrepreneur is an employee who has been "involved in the development of new business activities for their employer, such as establishing a new outlet or subsidiary, or launching new products and new product-market combinations $[\ldots]$ during the last 2 years" (Martiarena, 2013, p. 31).

Because there is no certain way to know if a potential respondent is a corporate or an independent entrepreneur ex ante, a screening question, consistent with the criteria mentioned above, was developed which asked the respondents to identify themselves either as an independent entrepreneur, a corporate entrepreneur, or "Other". Respondents who chose "Other" had an option to provide an explanation for their choice. Responses recorded by this group were used in the data analysis only after a close match between the job explanation provided and the definition of a corporate or an independent entrepreneur was established by the researcher. Moreover, all respondents' job titles were checked against the "entrepreneur type" selected and incompatible entries were excluded from analysis. An online survey using a third-party data collection service (Qualtrics) was used to administer the survey to the respondents. A total of 386 responses were recorded, from which only 197 were complete. Checking the data for outliers reduced the sample size to 172. Finally, a repeated measures (or test-retest) reliability analysis, using a 0.45 threshold as a moderate 
correlation level, yielded a final sample size of 157 (comprising 77 independent entrepreneurs and 80 corporate entrepreneurs). Because each respondent evaluated 16 estimation profiles, a total of 1232 observations for the independent group and a total of 1280 observations for the corporate group were recorded. The effective sample size (ESS) for each group is the number of statistically independent observations - which is the total number of observations adjusted for within-individual correlations (or intra-class correlations). The intra-class correlation coefficient (ICC) in this study is the proportion of variance in opportunity attractiveness that can be attributed to correlations between several observations within a single individual. Using equation 2, ICC values for the independent sample and the corporate sample are 0.22 and 0.26 , respectively. Using equation 3 , proposed by Diggle, Liang, and Zeger (1994), effective sample size is 248 for the independent sample and 268 for the corporate sample. Given a medium effect size of 0.3 for both samples and using a 0.05 significance level, power was calculated to be 0.89 for the independent sample and 0.91 for the corporate sample (both above the conventional threshold of 0.8 suggested by Cohen (2013)). Even using the actual sample sizes, power was calculated to be 0.77 for the independent group and 0.78 for the corporate group. It is also worth mentioning that similar studies (such as Haynie, Shepherd, \& McMullen, 2009; Holland \& Shepherd, 2013; Shepherd \& Zacharakis, 1997) have used comparable sample sizes with similar number of observations per individual. 


\section{Equation 2}

$$
I C C=\frac{\tau_{00}}{\tau_{00}+\sigma^{2}}
$$

Where:

$\tau_{00}=$ level -2 residual variance

$\sigma^{2}=$ level-1 residual variance

\section{Equation 3}

$$
E S S=\frac{n \times m}{(1+(m-1) \times I C C)}
$$

Where:

$\mathrm{n}=$ number of participants

$\mathrm{m}=$ number of repeated measures for each participant

Table 2 displays descriptive statistics data for the corporate and independent samples. Whereas there is no remarkable difference between the two groups of respondents in terms of gender and age, corporate entrepreneurs are from a more diverse ethnic background, and, on average, are more educated, have more years of industry experience, and have greater entrepreneurial experience. The most noticeable differences between the two groups, however, are related to firm size and firm revenue. Whereas only 3.9 percent of independent entrepreneurs run firms with over 500 employees, 43.2 percent of corporate entrepreneurs are employees of firms with such a minimum size. Moreover, whereas only 10.4 percent of independent entrepreneurs reported an average annual revenue of over ten 
million dollars, 60.5 percent of corporate entrepreneurs worked for firms whose average annual revenue exceeded this amount. These data show that the screening question in the beginning of the survey has effectively classified the respondents into the appropriate entrepreneurial group. Internal corporate venturing is more likely to take place in a large firm, with high revenues, due to high resource demands. There is also precedence in the prior research for using samples from the fortune 500 (e.g. Klavans, Shanley, \& Evan, 1985; Von Hippel, 1977) and samples of a country's largest firms (e.g. Thornhill \& Amit, 2001) to study internal corporate venturing activities. Conversely, independent entrepreneurs usually lack economies of scale and face several resource constraints. Therefore, this group of entrepreneurs are expected to run relatively small firms-i.e. firms with less than 500 employees. This size limit is consistent with US Small Business Administration size standards.

TABLE 2: Descriptive Statistics for the two samples

\begin{tabular}{ccc}
\hline & Independent Entrepreneur & Corporate Entrepreneur \\
\cline { 2 - 3 } Male & $51.9 \%$ & $51.8 \%$ \\
White & $80.5 \%$ & $74.1 \%$ \\
Average Age & 42.92 & 41.38 \\
Some college-level Education & $89.6 \%$ & $92.6 \%$ \\
Average Industry Experience \\
(in years) \\
Average number of ventures \\
founded \\
Over 500 Employees
\end{tabular}




\section{Variables and Measures}

Level 1: Opportunity assessment. An entrepreneur's assessment of a conjoint scenario is decomposed into a coefficient for every attribute of an opportunity and an intercept. The intercept represents an entrepreneur's willingness to pursue an opportunity regardless of level of the four attributes and their interactions (Shepherd et al., 2013). The attributes of an opportunity - i.e. resource-relatedness, entry scale, novelty, and knowledge of customer demand - each vary on two levels (high or low) and are characterized as follows:

(1) When resource-relatedness is high, the resources required for exploiting an opportunity are already at the entrepreneur's disposal or are complementary to the existing resource endowments of the entrepreneur; when resourcerelatedness is low, the resources required for exploiting an opportunity are rarely at the entrepreneur's disposal and have little complementarity to the existing resource endowments of the entrepreneur.

(2) When entry scale is high, an entrepreneur targets numerous geographical markets and a large number of customers at market entry; when entry scale is low, an entrepreneur targets a specific geographical market or a limited number of customers at market entry.

(3) When novelty is high, the new product or service will be highly different from the existing products or services in a market; when novelty is low, the new product or service will be similar to the existing products or services in a market. 
(4) When knowledge of customer demand is high, an entrepreneur is quite certain that there will be substantial future demand for the new product or service; when knowledge of customer demand is low, an entrepreneur is uncertain that there will be substantial future demand for the new product or service.

A sample opportunity profile is shown in table 3. In this sample profile, resource relatedness is high, entry scale is low, novelty is high, and knowledge of customer demand is low.

TABLE 3: Sample Opportunity Profile

\begin{tabular}{|c|c|c|}
\hline Opportunity Attribute & LEVEL & Interpretation \\
\hline Resource Relatedness & $\mathrm{HIGH}$ & $\begin{array}{l}\text { The resources required to exploit this opportunity are } \\
\text { already at your/your organization's disposal or are } \\
\text { complementary to your/your organization's existing } \\
\text { resource endowments. }\end{array}$ \\
\hline Entry Scale & LOW & $\begin{array}{l}\text { You will target a specific geographical market or a } \\
\text { limited number of customers at market entry. }\end{array}$ \\
\hline Novelty & HIGH & $\begin{array}{l}\text { The new product or service will be highly different } \\
\text { from the existing products or services in the market. }\end{array}$ \\
\hline $\begin{array}{l}\text { Knowledge of Customer } \\
\text { Demand }\end{array}$ & LOW & $\begin{array}{l}\text { You are uncertain that there is substantial future } \\
\text { demand for the new product or service. }\end{array}$ \\
\hline
\end{tabular}

Level 2: Perceived environmental dynamism. Respondents were asked to indicate their perceptions of dynamism in the external environment using a five-item scale developed by Miller and Friesen (1982). Scale reliability analysis returned a Chronbach's alpha of 0.66 for the independent sample and 0.71 for the corporate sample (close to Miller and Friesen's (1982) reliability value of 0.74). A subjective measure of 
dynamism is preferred over an objective measure in this study because an entrepreneur's perception of the environment (rather than the actual circumstances in the environment) is what directly affects his decision to pursue/abandon an opportunity. Moreover, as stated earlier, an entrepreneur's assessment of environmental dynamism prior to assessing the opportunity profiles allows me to capture the moderating effect of dynamism on opportunity attractiveness more effectively. Responses were recorded using a 7-point Likert scale.

Level 2: Perceived industry munificence. Respondents assessed industry munificence using a seven-item scale developed by Sutcliffe (1994) and based on the work by Glick, Huber, Miller, Doty, and Sutcliffe (1990). The reverse-coded items in the original questionnaire were reworded to straight-scored items. Chronbach's alpha value was 0.88 for both groups (consistent with Sutcliffe's (1994) reported value of 0.88). The same reasoning for choosing a subjective measure for environmental dynamism applies here. Responses were recorded using a 7-point Likert scale.

Control Variables. I followed the example of previous studies (e.g. Haynie, Shepherd, \& McMullen, 2009; Shepherd et al., 2013) in selecting control variables. Control variables at the individual-level consist of age, gender, ethnicity, industryspecific experience, entrepreneurial experience (measured by number of previous ventures created), education, entrepreneurial self-efficacy (measured by a four-item scale developed by Zhao et al. (2005)), and regulatory focus (measured by a 8 -item scale adapted from Higgins et al. (2001)). I included industry type, revenue, firm age, and firm size (measured by the number of employees) as extra control variables. 
The measure of entrepreneurial self-efficacy used in this study has been shown to strongly relate to Chen et al.'s (1998) well-known measure of entrepreneurial selfefficacy. Internal consistency values exceeded the value of 0.78 reported by Zhao et al. (2005) ( $\alpha=0.81$ for the independent group and $\alpha=0.80$ for the corporate group). Results of the confirmatory factor analysis for the regulatory focus construct, using AMOS 26, revealed poor fit for both groups $\left(\chi^{2}=84.73, p<0.001\right.$ for the independent group and $\chi^{2}=52.27, p<0.001$ for the corporate group). Therefore, I decided not to include this construct in the analysis. 


\section{CHAPTER 4: ANALYSIS AND RESULTS}

In this chapter, I present the results of the study. First, I present the results of the analyses with regard to the three groups of hypothesized relationships - i.e. main effect of opportunity attributes, interaction effects among opportunity attributes, and moderating effect of environmental conditions. Second, I provide the results of the post-hoc analysis for the effect of non-hypothesized relationships - involving interactions among opportunity attributes, and moderating effect of environmental conditions and individuallevel characteristics - on opportunity attractiveness.

\section{Results for the Hypothesized Relationships}

Tables 4 and 5 report the means, standard deviations, and correlations between variables at the individual level for the independent sample and the corporate sample, respectively. 
TABLE 4: Means, Standard Deviations, and Correlations for the Independent Sample

\begin{tabular}{|c|c|c|c|c|c|c|c|c|}
\hline Variables & Mean & s.d. & 1 & 2 & 3 & 4 & 5 & 6 \\
\hline 1. Age & 42.92 & 14.12 & 1 & & & & & \\
\hline 2. Industry Experience & 11.58 & 10.13 & $.57^{* *}$ & 1 & & & & \\
\hline $\begin{array}{l}\text { 3. Entrepreneurial } \\
\text { Experience }\end{array}$ & 2.98 & 1.80 & .05 & -.09 & 1 & & & \\
\hline 4. Perceived Dynamism & 4.23 & 1.10 & .04 & -.12 & $.29^{*}$ & 1 & & \\
\hline 5. Perceived Munificence & 5.21 & 1.09 & .03 & -.13 & $.29^{*}$ & $.51^{* *}$ & 1 & \\
\hline $\begin{array}{l}\text { 6. Entrepreneurial Self- } \\
\text { efficacy }\end{array}$ & 3.93 & 0.78 & -.04 & -.02 & $.27^{*}$ & $.40^{* *}$ & $.58^{* *}$ & 1 \\
\hline
\end{tabular}

TABLE 5: Means, Standard Deviations, and Correlations for the Corporate Sample

\begin{tabular}{|c|c|c|c|c|c|c|c|c|}
\hline Variables & Mean & s.d. & 1 & 2 & 3 & 4 & 5 & 6 \\
\hline 1. Age & 41.38 & 12.11 & 1 & & & & & \\
\hline 2. Industry Experience & 13.96 & 11.45 & $.78^{* *}$ & 1 & & & & \\
\hline $\begin{array}{l}\text { 3. Entrepreneurial } \\
\text { Experience }\end{array}$ & 3.45 & 2.18 & $-.23^{*}$ & -.005 & 1 & & & \\
\hline 4. Perceived Dynamism & 4.58 & 1.19 & .19 & -.002 & -.001 & 1 & & \\
\hline 5. Perceived Munificence & 5.24 & 1.08 & -.04 & -.11 & -.09 & $.24^{*}$ & 1 & \\
\hline $\begin{array}{l}\text { 6. Entrepreneurial Self- } \\
\text { efficacy }\end{array}$ & 4.02 & 0.75 & -.20 & -.10 & .22 & .09 & $.53^{* *}$ & 1 \\
\hline
\end{tabular}

In order to establish the need for conducting a multi-level analysis of the data in this dissertation, regression's independence of responses assumption has to be checked. As stated earlier in chapter 3, the intra-class correlation coefficient (ICC) is used to test intra-person reliability when several observations/responses from an individual are longitudinally recorded in a study. Generally, ICC values over 0.1 indicate that the 
independence of responses assumption has been violated and correlation between responses within an individual has to be accounted for to allow independence among observations. Table 6 displays the unconditional (intercept-only) model for both samples. The ICC values (calculated using equation 3.1) both exceed the 0.1 conventional threshold; therefore, there is a need for a multilevel inspection of the dependent construct of this study - i.e. willingness to pursue the opportunity.

\section{TABLE 6: Unconditional (Intercept-only) Model for Independent and Corporate Samples}

\begin{tabular}{lcc}
\hline Variance & Independent Sample & Corporate Sample \\
\hline Level-1 residual variance, $\boldsymbol{\sigma}^{\mathbf{2}}$ & $3.55(1.88)$ & $4.54(2.13)$ \\
Level-2 residual variance, $\boldsymbol{\tau}_{\mathbf{0 0}}$ & $1.24(1.11)^{* * * *}$ & $1.28(1.13)^{* * *}$ \\
Intra-class Correlation & 0.26 & 0.22 \\
Coefficient & &
\end{tabular}

Tables 7 displays the effect of numerical control variables on the dependent variable of the study - i.e. willingness to pursue the opportunity - for independent and corporate samples. The results show that for independent entrepreneurs, gender, age of entrepreneur, industry experience, and entrepreneurial experience (measured by the number of ventures founded) significantly impact an entrepreneur's decision to invest in a new business opportunity, regardless of the effect of opportunity attributes. The effect of age and industry experience is minuscule and can be neglected but gender and entrepreneurial experience have noticeable impacts on the dependent variable. Because gender was dummy-coded as " $1=$ Male" and " $0=$ Female", the positive effect of gender on the dependent variable of the study translates to a relatively higher propensity of male independent entrepreneurs to invest in a new business idea. Independent entrepreneurs 
with higher entrepreneurial experience are also more likely to start new businesses. The effect of entrepreneurial self-efficacy for this group is not significant.

For corporate entrepreneurs, the only control variables that had a significant effect on an entrepreneur's likelihood to invest in a new opportunity was industry experience whose effect was miniscule.

TABLE 7: Controls-only Model for Independent and Corporate Samples

\begin{tabular}{lcccc}
\hline Variables & Independent Sample & \multicolumn{2}{c}{ Corporate Sample } \\
\hline Intercept & $2.83^{* * *}(0.19)$ & $3.51^{* * *}(0.26)$ \\
Gender & $0.67^{* *}(0.23)$ & 0.06 & $(0.26)$ \\
Age & $-0.02^{*}$ & $(0.008)$ & -0.003 & $(0.01)$ \\
Industry Experience & $-0.02^{*}$ & $(0.01)$ & $-0.03^{\Gamma}$ & $(0.02)$ \\
Entrepreneurial Experience & $0.15^{*}$ & $(0.07)$ & 0.10 & $(0.06)$ \\
Entrepreneurial Self-efficacy & 0.06 & $(0.16)$ & 0.12 & $(0.17)$ \\
\hline
\end{tabular}

${ }^{\text {г }} p<0.1,{ }^{*} p<0.05,{ }^{* *} p<0.01,{ }^{* * *} p<0.001$

Tables 8 and 9 summarize the results of the HLM analysis for independent and corporate samples, respectively. Non-significant control variables in each sample were trimmed before proceeding with the HLM analysis. The results for both samples are presented under the following categories: 1) base model (predictors and trimmed controls), 2) interactions model (predictors, trimmed controls, and two-way interactions), and 3) full model (predictors, trimmed controls, two-way interactions, and moderators). 
TABLE 8: HLM Results for the Independent Sample (Random Effects and Standard Errors)

\begin{tabular}{|c|c|c|c|}
\hline Variables & Base Model & Interactions Model & Full Model \\
\hline Intercept, $\boldsymbol{\beta}_{00}$ & $3.77^{* * *}(0.21)$ & $3.76^{* * *}(0.20)$ & $3.76^{* * *}(0.21)$ \\
\hline Resource Relatedness & $1.51^{* * *}(0.15)$ & $1.52^{* * *}(0.15)$ & $1.52^{* * *}(0.15)$ \\
\hline Entry Scale & $0.76^{* * *}(0.14)$ & $0.77^{* * *}(0.14)$ & $0.77^{* * * *}(0.14)$ \\
\hline Novelty & $1.15^{* * *}(0.14)$ & $1.16^{* * *}(0.14)$ & $1.16^{* * *}(0.14)$ \\
\hline Knowledge of Demand & $1.92^{* * *}(0.22)$ & $1.93^{* * *}(0.22)$ & $1.93^{* * *}(0.22)$ \\
\hline Gender & $0.74^{*} \quad(0.30)$ & $0.74^{*} \quad(0.31)$ & $0.74^{*} \quad(0.31)$ \\
\hline Entrepreneurial Experience & $0.19^{*}(0.08)$ & $0.19^{*}(0.08)$ & $0.19^{*}(0.08)$ \\
\hline Novelty $\times$ Resource Relatedness & & $0.24 \quad(0.15)$ & $0.27^{\Gamma} \quad(0.15)$ \\
\hline Novelty $\times$ Entry Scale & & $(0.15)$ & $0.29^{*}$ \\
\hline Novelty $\times$ Knowledge of Demand & & $(0.18)$ & $0.33^{*}$ \\
\hline Novelty $\times$ Dynamism & & & $(0.11)$ \\
\hline Entry Scale $\times$ Dynamism & & & $(0.14)$ \\
\hline Entry Scale $\times$ Munificence & & & $(0.16)$ \\
\hline
\end{tabular}

${ }^{\text {г }} p<0.1,{ }^{*} p<0.05,{ }^{* *} p<0.01,{ }^{* * *} p<0.001$ 
TABLE 9: HLM Results for the Corporate Sample (Random Effects and Standard Errors)

\begin{tabular}{|c|c|c|c|}
\hline Variables & Base Model & Interactions Model & Full Model \\
\hline Intercept, $\boldsymbol{\beta}_{\mathbf{0 0}}$ & $3.97^{* * *}(0.27)$ & $3.97^{* * *}(0.26)$ & $4.00^{* * * *}(0.27)$ \\
\hline Resource Relatedness & $0.90^{* * *}(0.15)$ & $0.90^{* * *}(0.15)$ & $0.92^{* * *}(0.15)$ \\
\hline Entry Scale & $0.34^{* *}(0.11)$ & $0.35^{* *}(0.11)$ & $0.35^{* * *}(0.11)$ \\
\hline Novelty & $0.73^{* * *}(0.12)$ & $0.73^{* * *}(0.12)$ & $0.74^{* * * *}(0.13)$ \\
\hline Knowledge of Demand & $1.30^{* * *}(0.19)$ & $1.30^{* * *}(0.19)$ & $1.31^{* * *}(0.19)$ \\
\hline Resource Relatedness $\times$ Novelty & & $0.07 \quad(0.16)$ & $(0.16)$ \\
\hline Novelty $\times$ Entry Scale & & $0.35^{*} \quad(0.14)$ & $0.37^{* *} \quad(0.14)$ \\
\hline Novelty $\times$ Knowledge of Demand & & $0.001 \quad(0.19)$ & $0.001 \quad(0.19)$ \\
\hline Novelty $\times$ Dynamism & & & $(0.12)$ \\
\hline Entry Scale $\times$ Dynamism & & & $0.08 \quad(0.15)$ \\
\hline Entry Scale $\times$ Munificence & & & $0.28^{*} \quad(0.13)$ \\
\hline
\end{tabular}

${ }^{*} p<0.05,{ }^{* *} p<0.01,{ }^{* * *} p<0.001$

\section{Results for the main effects}

The coefficients for the intercept for the independent sample $(\beta=3.76, p<$ $0.001)$ and the corporate sample $(\beta=4.00, p<0.001)$ are both significant. As stated in chapter 3, the intercept represents an entrepreneur's willingness to pursue an opportunity regardless of level of the four attributes and their interactions. Therefore, corporate entrepreneurs in this sample, on average, are more motivated to pursue new venture ideas. Next, I will discuss the effect of opportunity attributes on the willingness of an entrepreneur to invest in a new business idea.

Hypothesis 1 predicts that the effect of resource relatedness on pursuit of an opportunity is larger among independent entrepreneurs. The coefficients for the independent sample $(\beta=1.52, p<0.001)$ and the corporate sample $(\beta=0.92, p<$ 
0.001) are both positive and significant, with the coefficient for the independent sample being larger. Using equation 3.1, the difference in coefficients is also significant $(z=$ $2.83, p<0.05)$. Therefore, hypothesis 1 is supported. Hypothesis 2 predicts that entry scale has a more deterring effect on pursuit of an opportunity among independent entrepreneurs. Contrary to the direction of the hypothesized relationship, entry scale had a significant positive effect on the willingness of entrepreneurs to pursue an opportunity in both the independent sample $(\beta=0.77, p<0.001)$ and the corporate sample $(\beta=$ $0.35, p<0.001)$. Therefore, hypothesis 2 was not supported. Nevertheless, the difference in likelihood between the two groups turned out to be significant $(z=2.36, p<0.05)$. In other words, independent entrepreneurs, relative to corporate entrepreneurs, were significantly more likely to pursue large-scale opportunities. Hypothesis 3 predicts that novelty has a greater positive effect on pursuit of an opportunity among independent entrepreneurs. The coefficients for the independent sample $(\beta=1.16, p<0.001)$ and the corporate sample $(\beta=0.74, p<0.001)$ are both positive and significant, with the coefficient for the independent sample being larger. The difference in coefficients is also significant $(z=2.20, p<0.05)$. Therefore, hypothesis 3 is supported. Hypothesis 4 predicts that knowledge of customer demand has a greater positive effect on pursuit of an opportunity among independent entrepreneurs. The coefficients for the independent sample $(\beta=1.93, p<0.001)$ and the corporate sample $(\beta=1.31, p<0.001)$ are both positive and significant, with the coefficient for the independent sample being larger. The difference in coefficients is also significant $(z=1.88, p<0.05)$. Therefore, hypothesis 4 is also supported. 
Table 10 summarizes the preferences for the opportunity attributes among the two groups of entrepreneurs. First, the order of importance of the attributes is the same among corporate and independent entrepreneurs and is as follows: 1) knowledge of demand, 2) resource relatedness, 3) novelty, and 4) entry scale. Therefore, independent and corporate entrepreneurs in this study displayed similar decision-making preferences and priorities with regard to opportunity characteristics. Second, every attribute has a larger coefficient for the independent group. In other words, opportunity attributes have a greater impact on opportunity attractiveness among independent entrepreneurs.

\begin{tabular}{|c|c|c|c|}
\hline \multicolumn{4}{|c|}{$\begin{array}{c}\text { TABLE 10: Opportunity Attribute Preferences and their across-group Relative } \\
\text { Weight }\end{array}$} \\
\hline Attribute & $\begin{array}{c}\text { Preference for } \\
\text { Independent Group }\end{array}$ & $\begin{array}{c}\text { Preference for } \\
\text { Corporate Group }\end{array}$ & $\begin{array}{l}\text { Coefficient } \\
\text { larger for }\end{array}$ \\
\hline Knowledge of Demand & 1 & 1 & $\begin{array}{l}\text { Independent } \\
\text { Entrepreneur }\end{array}$ \\
\hline Resource Relatedness & 2 & 2 & $\begin{array}{l}\text { Independent } \\
\text { Entrepreneur }\end{array}$ \\
\hline Novelty & 3 & 3 & $\begin{array}{l}\text { Independent } \\
\text { Entrepreneur }\end{array}$ \\
\hline Entry Scale & 4 & 4 & $\begin{array}{l}\text { Independent } \\
\text { Entrepreneur }\end{array}$ \\
\hline
\end{tabular}

\section{Results for the two-way interactions among predictors}

Hypothesis 5 predicts that the effect of novelty on attractiveness of a resourcerelated opportunity is stronger among independent entrepreneurs than among corporate entrepreneurs. The coefficient for the interaction term "Novelty $\times$ Resource Relatedness" is positive for both samples but is only significant for the independent sample $(\beta=0.27$, 
$p<0.1)$. In other words, resource relatedness increases the attractiveness of a novel opportunity only among independent entrepreneurs. However, because the difference is significant, hypothesis 5 is supported. Hypothesis 6 predicts that the effect of novelty on attractiveness of a large-scale opportunity is stronger among independent entrepreneurs than among corporate entrepreneurs. The coefficient for the interaction term "Novelty $x$ Entry Scale" is significant for the independent sample $(\beta=0.29, p<0.05)$ and the corporate sample $(\beta=0.35, p<0.05)$. However, the difference in the two coefficients is not significant $(z=0.34, p>0.1)$. Therefore, hypothesis 6 is not supported. Hypothesis 7 predicts that the effect of novelty on attractiveness of an opportunity with a low perceived knowledge of demand is stronger among independent entrepreneurs than among corporate entrepreneurs. The coefficient for the interaction term "Novelty $\times$ Knowledge of Demand" is only significant for the independent group $(\beta=0.33, p<0.05)$. However, because the difference term is still significant, hypothesis 7 is supported. This shows that novelty positively interacts with knowledge of demand in shaping the perception of an opportunity among independent entrepreneurs. In other words, opportunity novelty increases opportunity attractiveness among independent entrepreneurs even when perceived future demand is low.

\section{Results for the moderation effects}

Hypothesis 8 predicts that the moderating effect of dynamism on pursuit of a novel opportunity is greater among corporate entrepreneurs than among independent entrepreneurs. The coefficient for the moderation effect "Novelty $\times$ Dynamism" is not significant for any of the groups. Therefore, hypothesis 8 is not supported. Hypothesis 9 predicts that the moderating effect of dynamism on pursuit of a large-scale opportunity is 
greater among independent entrepreneurs as compared to corporate entrepreneurs. The coefficient for the moderation effect "Entry Scale $\times$ Dynamism" is not significant for any of the samples. Hence, hypothesis 9 is not supported. Hypothesis 10 predicts that the effect of environmental munificence on pursuit of a large-scale opportunity is larger among independent entrepreneurs than among corporate entrepreneurs. Whereas the moderation effect "Entry Scale $\times$ Munificence" is significant for the corporate sample $(\beta=0.28, p<0.05)$, the effect is not significant for the independent sample. Therefore, hypothesis 10 is not supported.

\section{Post hoc Analysis Results}

Because several two-way interaction and moderation effects were not theorized in this study, I performed a post hoc analysis to test for the significance of any of these nonhypothesized effects. Below, I will separately discuss these relationships for the two samples.

\section{Post hoc findings for the independent group}

Table 11 shows the significant post hoc relationships for the independent sample. The interaction of entry scale and knowledge of demand turned out to be positive and significant $(\beta=0.33, p<0.05)$. This could mean that independent entrepreneurs are more likely to launch a large-scale project when they can perceive a high future demand for a product. Environmental munificence positively moderated the effect of resource relatedness $(\beta=0.47, p<0.01)$ and novelty $(\beta=0.23, p<0.1)$ on pursuit of an opportunity. One can discuss that resource-related and novel opportunities are more favorable to independent entrepreneurs when they believe resources for growth are abundant in an industry. Being male negatively moderated the effect of resource 
relatedness $(\beta=-0.48, p<0.1)$ and knowledge of demand $(\beta=-0.88, p<0.05)$ among independent entrepreneurs. Therefore, male independent entrepreneurs, might underestimate the importance of these two attributes when assessing the viability of an opportunity. Finally, entrepreneurial experience negatively moderated the effect of resource relatedness $(\beta=-0.12, p<0.1)$, novelty $(\beta=-0.23, p<0.01)$, and knowledge of customer demand $(\beta=-0.26, p<0.05)$ among independent entrepreneurs. One could argue that experienced independent entrepreneurs might understate or overlook the importance of these three attributes when evaluating a new business idea.

TABLE 11: Post hoc results for the Independent Sample (with Standard Errors)

\begin{tabular}{lccc}
\hline Variables & Interaction Effects & $\begin{array}{c}\text { Moderation } \\
\text { Effects }\end{array}$ \\
\hline Entry Scale $\times$ Knowledge of Demand & $0.33^{*}(0.15)$ & & \\
Resource Relatedness $\times$ Munificence & & $0.47^{* *} \quad(0.15)$ \\
Resource Relatedness $\times$ Gender & $-0.48^{\text {厂 }} \quad(0.28)$ \\
Resource Relatedness $\times$ Entrepreneurial Experience & $-0.12^{\text {厂 }} \quad(0.06)$ \\
Novelty $\times$ Munificence & $0.23^{\text {厂 }} \quad(0.12)$ \\
Novelty $\times$ Entrepreneurial Experience & & $-0.23^{* *}(0.07)$ \\
Knowledge of Demand $\times$ Gender & & $-0.88^{*}$ & $(0.44)$ \\
Knowledge of Demand $\times$ Entrepreneurial Experience & & $-0.26^{*}$ & $(0.11)$ \\
\hline
\end{tabular}

$$
{ }^{\mathrm{r}} p<0.1,{ }^{*} p<0.05,{ }^{* *} p<0.01
$$

\section{Post hoc findings for the corporate group}

Table 12 shows the significant post hoc relationships for the corporate sample.

The interaction of resource relatedness and knowledge of demand is positive and significant for corporate entrepreneurs $(\beta=0.47, p<0.001)$. This could indicate that resource relatedness of an opportunity becomes more important to a corporate 
entrepreneur when his/her perceived future demand for the opportunity is higher.

Environmental munificence positively moderated the effect of resource relatedness $(\beta=$ 0.53, $p<0.001)$, novelty $(\beta=0.60, p<0.001)$, and knowledge of demand $(\beta=0.52, p$ $<0.05$ ), on pursuit of a focal opportunity. In other words, an intrapreneur's assessment of three of the four opportunity attributes partly depends on resource abundance in the environment. The interaction of entry scale and self-efficacy was positive and significant $(\beta=0.27, p<0.1)$. I propose that corporate entrepreneurs with high self-efficacy are more likely to act upon and engage in a large-scale opportunity. Finally, entrepreneurial experience negatively moderated the effect of resource relatedness $(\beta=-0.16, p<0.05)$ and entry scale $(\beta=-0.13, p<0.05)$ on pursuit of a new business idea. One possible explanation could be that more experienced intrapreneurs might attach a lower weight to these two criteria when assessing a new business idea.

\section{TABLE 12: Post hoc results for the Corporate Sample (with Standard Errors)}

\begin{tabular}{lccc}
\hline Variables & Interaction Effects & \multicolumn{2}{c}{$\begin{array}{c}\text { Moderation } \\
\text { Effects }\end{array}$} \\
\hline Resource Relatedness $\times$ Knowledge of Demand & $0.47^{* * *}(0.13)$ & $0.53^{* * *}(0.15)$ \\
Resource Relatedness $\times$ Munificence & & $-0.16^{*}(0.07)$ \\
Resource Relatedness $\times$ Entrepreneurial Experience & & $0.27^{\text {厂 }}(0.15)$ \\
Entry Scale $\times$ Self Efficacy & $-0.13^{*}(0.06)$ \\
Entry Scale $\times$ Entrepreneurial Experience & & $0.60^{* * *}(0.13)$ \\
Novelty $\times$ Munificence & & $0.52^{*}(0.24)$ \\
Knowledge of Demand $\times$ Munificence & & \\
\hline
\end{tabular}

$$
{ }^{\text {г }} p<0.1,{ }^{*} p<0.05,{ }^{* * *} p<0.001
$$




\section{CHAPTER 5: DISCUSSION AND CONCLUSION}

Shane and Venkataraman (2000) contend that the process of entrepreneurship consists of three major stages: discovery, evaluation, and exploitation. Opportunity evaluation, therefore, is a critical step in the entrepreneurial process and is the main precursor to entrepreneurial action. Through opportunity evaluation, an entrepreneur assesses the feasibility and desirability of an opportunity and determines if a potentially profitable opportunity can be indeed an actionable opportunity for him/her (McMullen \& Shepherd, 2006). Whereas extensive research has been conducted in identifying the salient factors that affect opportunity-related decision-making among entrepreneurs, there is scarce knowledge on how this decision-making varies between corporate and noncorporate contexts. In this dissertation, I theorized and empirically tested the major differences in opportunity evaluation between corporate entrepreneurs and independent entrepreneurs. More specifically, I examined these differences with regard to three major categories of factors that are known to affect opportunity evaluation: 1) nature of an opportunity, 2) characteristics of individuals, and 3) environmental conditions. In this chapter, I will further discuss the findings of this research with reference to these three categories and will propose theoretical and practical implications of the study. I will conclude the chapter by explaining the limitations of this research and providing directions for relevant future studies. 


\section{Discussion of The Findings}

\section{Nature of an opportunity and opportunity attractiveness}

Nature of an opportunity refers to attributes and features of an opportunity over and beyond the effect of environmental conditions or an entrepreneur's characteristics. Opportunity attributes constitute the primary basis for evaluating the value-creating potential of an opportunity. In other words, a positive evaluation of an opportunity attribute(s) precedes any feasibility analysis by an entrepreneur. In this dissertation, I used four opportunity attributes - i.e. resource relatedness, entry scale, novelty, and knowledge of customer demand - to compare opportunity evaluation between corporate and independent entrepreneurs. The selection of these opportunity attributes was informed using two theoretical perspectives - i.e. resource availability and tolerance for uncertainty - that explain a great amount of variance in decision-making between corporate and non-corporate contexts. Results of my dissertation confirm that all four attributes studied positively impact perceptions of an opportunity among both groups of entrepreneurs - i.e. corporate entrepreneurs and independent entrepreneurs. In other words, opportunities with high levels of resource-relatedness, entry scale, novelty, and perceived future demand - compared with ones with lower levels of these attributes - are more likely to be pursued by entrepreneurs. However, the attributes studied presented varying effects on opportunity perceptions. Surprisingly, the order of attribute importance was the same for corporate and independent groups. In this section, first, I explain the direct effects of opportunity attributes in order of importance. Second, I discuss important interaction effects among opportunity attributes. 


\section{Direct effects of opportunity attributes}

\section{Knowledge of customer demand}

Knowledge of customer demand turned out to be the most important of the four attributes studied in evaluating an entrepreneurial opportunity, among both groups of entrepreneurs. Every successful marketing initiative should start with identification of a "market pain" - i.e. customers' real need - and the success of a new product launch lies in the true value the product proposes to the target customers (Crane, 2012). Uncertainty about the future demand has a hugely confounding effect on new venture investment decisions among entrepreneurs (Bhide, 2008; McKelvie et al., 2011). Whereas determining the competitive advantage of products in markets with unstable demand is a challenging task (Shepherd, 1999), early-stage venture funding in such markets is an added complication as traditional valuation models become inaccurate (Hsu, 2004). Moreover, when there is no clear demand for a new offering, activities such as product promotion and customer service will be of little use in securing a share of the market in the long run, following product launch (Crane, 2012). That said, adoption of a new product/service in the market always involves at least some level of uncertainty due to customers' lack of familiarity with the new offering and their reluctance to switch away from existing offerings. Part of the demand uncertainty also comes from entrepreneurs' partial knowledge about market dynamics and customer preferences and tastes. Therefore, entrepreneurs struggle with uncertainty over future demand when evaluating new venture ideas. However, this can vary among different individuals and in different contexts. Results of this study show that, of the four attributes studied, perceived knowledge of customer demand has the strongest impact on shaping attractiveness of an opportunity among both corporate and independent entrepreneurs. However, this effect 
was stronger for the independent group (as hypothesized), meaning that independent entrepreneurs were more concerned about the anticipated future demand when assessing the desirability of an opportunity. Customers' knowledge of a firm's offerings reduces uncertainty surrounding purchasing decisions (Choi \& Shepherd, 2004). Moreover, a firm's brand equity and image hugely impact consumers' perceptions of a firm's new offerings in the market (Zeithaml \& Bitner, 1996). As one would imagine, startups, compared to established organizations, would score less on these criteria because startups have yet to establish a loyal customer base and place their brand in the brand awareness set of target customers (Crane, 2012). Therefore, entrepreneurs in such startups prefer to pursue new venture ideas whose anticipated future demand is more certain. On the other hand, larger organizations have an established customer base and have a better understanding of customers' needs and desires (Morris et al., 2010) and, therefore, are better able to cope with unpredictability of demand for a new offering (compared to startups).

\section{Resource relatedness}

Resource relatedness was found to be the second important attribute in evaluating opportunities among corporate and independent entrepreneurs. According to the resourcebased view, firm-specific resources that are valuable, rare, inimitable, and organized can become the basis for sustained competitive advantage (Barney, 2014). The higher the similarity or complementarity between the resources required to implement an opportunity and the resources available to an entrepreneur, the more likely is an opportunity to result in a competitive advantage. Moreover, when an opportunity is resource-related, entrepreneurs and corporate entrepreneurs will have to spend relatively 
less time and capital to put together the initial resources required to exploit the opportunity. Not only the results of this study confirmed that resource-relatedness was a critical factor in evaluating an entrepreneurial opportunity among both groups of entrepreneurs, it was also confirmed that resource-relatedness mattered more to the independent group. Independent entrepreneurs are usually resource-constrained and have difficulty procuring financial, human capital, and other types of resources especially in the early stages of firm growth (Baker \& Nelson, 2005; Penrose, 1959). Therefore, a mismatch between the resources required to exploit the focal opportunity and the existing resources of the entrepreneur would cast doubt on feasibility of the opportunity. Established organizations, however, are relatively less intimidated by a resource mismatch as they can attain the missing resources by tapping into their financial capital, established market power, and extensive network ties (Morris et al., 2010). Established organizations that have slack resources - i.e. "potentially utilizable resources that can be diverted or redeployed for the achievement of organizational goals" (George, 2005, p. 661) - have also been shown to experience more flexibility and confidence in pursuing a wide range of strategic initiatives, including seizing unforeseen new business opportunities (Fadol, Barhem, \& Elbanna, 2015; Salge, 2012; Tan \& Peng, 2003). Overall, corporate entrepreneurs, relative to independent entrepreneurs, appear to attach a lower weight to resource complementarity when deciding to pursue an opportunity.

\section{Novelty}

Novelty was shown to be the third important attribute in evaluating an entrepreneurial opportunity by both groups of entrepreneurs. Novelty refers to the degree to which a new product/service introduced to the market is different from the existing 
ones (Amason et al., 2006). Entrepreneurial offerings are novel offerings because they are meant to be different from those of competitors and aim at changing the ways in which customers are served. However, the degree of novelty depends on the extent of innovation used to develop the product/service. New offerings that are based on continuous (or incremental) innovation involve minor refinements or improvements to existing combinations and have little or no effect on existing consumption patterns of customers. But new offerings that are based on discontinuous (or radical) innovation dramatically change existing combinations and have a hugely disruptive effect on consumer consumption behaviors (Amason et al., 2006; Cheah, 1990; Crane, 2012). Results of this dissertation showed that corporate and independent entrepreneurs factored in novelty when evaluating a new venture idea. However, more novel opportunities were more attractive to independent entrepreneurs, as hypothesized. Novelty can introduce uncertainty in the product development process as resources need to be recombined/rearranged in a totally new way (Fleming, 2001). On the one hand, large organizations prefer to use existing patterns and established routines to expand their business lines and are more cautious about pursuing risky paths, relative to startups. On the other hand, a highly novel opportunity might fail to attract enough support from top managers and organizational stakeholders as both constituencies see little merit in organizational resources being invested in opportunities with uncertain outcomes (Morris et al., 2010). Independent entrepreneurs, however, experience considerable flexibility and freedom in experimenting and exploring novel opportunities and are more adept at making decisions in unconventional and uncertain circumstances (Burns \& Stalker, 1961; Corbett \& Hmieleski, 2007; Morris et al., 2010). 


\section{Entry scale}

Scale of entry turned out to be the fourth important attribute affecting opportunity attractiveness among corporate and independent entrepreneurs. Scale of entry refers to the number of geographical markets and the number/range of customers targeted by a firm/an entrepreneur when introducing a product/service. Whereas in a small-scale entry, a specific geographical market and a limited number of customers/customer groups are targeted, a large-scale entry involves penetrating several geographical markets and targeting a large number of customers. Prior research has established a positive association between scale of entry and survivability and performance of new ventures (Biggadike, 1989; Cooper et al., 1986; Hobson \& Morrison, 1983; MacMillan \& Day, 1987; Miller \& Camp, 1985). However, a large-scale entry is not always a feasible option as it requires extensive mobilization of resources and huge amounts of initial investment (Fan, 2010; McDougall, 1989). Established firms, as opposed to startups, appear to be in a stronger position to make such entries because they possess economies of scale and scope and have extensive network ties that facilitate market penetration. But contrary to these contentions, results of this study showed that independent entrepreneurs were more likely than their corporate counterparts to pursue large-scale opportunities. At first glance, this finding might appear surprising, even counterintuitive. However, the research on entrepreneurs' overconfidence might provide some useful insights in this regard. Overconfidence refers to a decision-maker's optimism about his/her initial assessment of a situation and his/her reluctance to effectively take in additional information about that situation to modify the initial assessment (Alpert \& Raiffa, 1982; Fischhoff, Slovic, \& Lichtenstein, 1977). Founders who are overconfident, overestimate the chances of success for their new ventures and have unrealistic perceptions of their ability to generate 
wealth (Hayward, Shepherd, \& Griffin, 2006). These founders also tend to underestimate the resource requirements of the environment and the risks associated with mobilizing the resources (Hayward et al., 2006; Shane \& Stuart, 2002). In their study on decisionmaking differences between entrepreneurs and managers, Busenitz and Barney (1997) show why entrepreneurs are more overconfident than managers in large organizations. They reason that although entrepreneurs might not know all the facts about an opportunity and the way to exploit it, their overconfidence helps them capitalize on the idea before it is gone, by convincing potential stakeholders and bringing them on board. Managers, on the other hand, usually rely on available decision-support tools and past performance data to make more accurate decisions. Forbes (2005) also shows that founder-managers of new ventures are more overconfident than managers who are not founders. Drawing an analogy, one can reason that independent entrepreneurs, who are founder-managers of new ventures, are expected to be more overconfident than corporate entrepreneurs, who operate in the context of a large organization and tend to make more calculated decisions that fit in with the grand policies of top management. Therefore, a possible reason for independent entrepreneurs' higher willingness to pursue large-scale opportunities would be these entrepreneurs' higher levels of overconfidence and their unrealistic (and even unreasonable) perceptions of their own abilities.

\section{Interaction effects among opportunity attributes}

Results of this study also revealed several significant interaction effects among opportunity attributes. These effects capture the simultaneous impact two opportunity attributes might have on perceptions of attractiveness of an opportunity. Stated differently, varying the level of one attribute might positively or negatively impact 
perceptions of another attribute. For independent entrepreneurs, novelty turned out to be positively interacting with the other three opportunity attributes - i.e. resourcerelatedness, entry scale, and knowledge of customer demand. This means that although novelty, alone, was the third important attribute for independent entrepreneurs in evaluating an opportunity, it significantly affected perceptions of all other attributes. In other words, the effect of resource-relatedness, entry scale, and future demand on attractiveness of an opportunity for independent entrepreneurs was strengthened when opportunity was also novel. Perhaps independent entrepreneurs are more attracted to a novel opportunity that has other features as well. In this sense, novelty could be considered a complementary (or even a pivotal) attribute for independent entrepreneurs.

For independent entrepreneurs, another positive interaction was found between knowledge of future demand and entry scale. As knowledge of future demand was previously found to be the most important attribute in this study, it was also found to have a positive effect on the relationship between scale of entry and opportunity attractiveness. Seemingly, independent entrepreneurs are more excited about large-scale opportunities that also promise more certain future demand. Although it was initially shown that independent entrepreneurs were more excited than corporate entrepreneurs to implement large-scale projects, it appears that their excitement levels are also contingent on their perceptions of future demand for that project. Large-scale projects with lower perceived customer demand might lose their appeal to independent entrepreneurs who have to commit extensive resources to initiate the project. This interaction effect was absent for the corporate entrepreneurs. As one might reason, corporations have larger financial, human capital, and organizational resource endowments and their decision to 
pursue a large-scale opportunity would be, relatively, less seriously affected by uncertainty over future demand.

For corporate entrepreneurs, a positive interaction effect was found between scale of entry and novelty. Similar to independent entrepreneurs, the weight corporate entrepreneurs attach to scale of entry depends on the level of novelty an opportunity entails. More importantly, for new venture ideas that need to be implemented in an initially larger scale, perceived novelty noticeably increases a positive perception of the idea among corporate entrepreneurs. Because implementation of large-scale projects necessitates extensive mobilization of resources (sometimes at various organizational levels), corporate managers might decide to exercise more prudence in pursuing such opportunities. Corporate entrepreneurs, likewise, might be reluctant to develop such ideas unless they believe the opportunity has the potential to offer a distinctive value to customers. Novel/unique products or services that deviate from existing offerings in the market are more likely to create a competitive edge for a firm (Crane, 2012) and provide a better justification for increased scale of implementation and larger resource investments. Results of this study also revealed a positive interaction effect between resource-relatedness of an opportunity and perceived future demand among the corporate group. This finding bears further evidence for the central role the perceived demand plays in shaping the expected value of a focal opportunity.

\section{Individual differences and opportunity attractiveness}

Individual differences - such as differences in personal motivation, domainspecific expertise, self-efficacy, optimism, entrepreneurial experience, etc. - have a significant effect on the decision of an entrepreneur to pursue (or abandon) an 
opportunity. We know that entrepreneurs pursue an opportunity based on their perceptions of feasibility and desirability of the opportunity (Krueger, 1993; Shapero, 1975). Perceptions of feasibility, however, vary among entrepreneurs and depend on individual characteristics, experiences, intentions, and states of mind. In my dissertation, I have explored the effects of the following individual-level factors on evaluation of opportunities by corporate and independent entrepreneurs: age, gender, industry experience, entrepreneurial experience, entrepreneurial self-efficacy, and regulatory focus. Among these variables, gender, entrepreneurial experience, and entrepreneurial self-efficacy turned out to have significant effects on intentions of entrepreneurs to pursue new venture ideas. Below, I discuss these effects.

\section{Gender}

Gender was shown to have a significant effect on the willingness to pursue an opportunity only among independent entrepreneurs. Results of this study showed that male independent entrepreneurs were significantly more likely than female independent entrepreneurs to pursue and invest in new venture ideas. This is consistent with the findings of the study conducted by Wilson, Kickul, and Marlino (2007) which revealed higher levels of entrepreneurial intentions among males. In the same vein, Gupta, Goktan, and Gunay (2014) demonstrated that when not presented with any stereotypical information or clue, men reported more favorable evaluations of a focal opportunity than women. Findings of this dissertation suggest that irrespective of the attributes of an opportunity or the circumstances in the external environment, male independent entrepreneurs are more likely than female independent entrepreneurs to pursue and implement new venture opportunities. Results of the post-hoc analysis also revealed 
negative moderating effect of gender on attractiveness of two of the four opportunity attributes - i.e. resource-relatedness and perceived knowledge of demand - among the independent entrepreneurs. When evaluating an opportunity from a resource-relatedness and a perceived future demand perspective, being male was associated with a decline in the likelihood to pursue the opportunity. In other words, resource-relatedness and certainty over future demand appeared to matter less to male independent entrepreneurs. A study by Artinger and Powell (2016) demonstrated higher inclination of male participants to overconfidence in entering new markets. The study by Robinson and Marino (2015) also suggests a negative association between overconfidence and risk perceptions of a new venture idea. Consistent with these findings, I suggest that male independent entrepreneurs' higher overconfidence might be the reason behind their underestimating or overlooking the importance of opportunity attributes such as resourcerelatedness and perceived future demand. Results of my dissertation revealed no significant association between gender and opportunity evaluation among corporate entrepreneurs.

\section{Entrepreneurial experience}

In this dissertation, entrepreneurial experience was measured by the number of ventures an entrepreneur had founded during his entire career. This individual-level variable was shown to have a positive but moderate effect on intentions of independent entrepreneurs to pursue new venture ideas (above and beyond the effect of opportunity attributes or environmental conditions). Independent entrepreneurs who had founded more ventures in the past were more likely to engage in new business opportunities. According to Baron and Ensley (2006), experienced entrepreneurs, as opposed to novice 
entrepreneurs, possess clearer and richer cognitive frameworks for evaluating new business opportunities. These authors show that experienced entrepreneurs have a better understanding of different dimensions of an opportunity and are more focused in their evaluations of a focal opportunity. Ucbasaran, Westhead, Wright, and Flores (2010) also show that entrepreneurs who have had more successful prior business ownership experiences are also more optimistic about creating new businesses in the future. It appears that as entrepreneurs become more experienced, they can imagine a clearer picture of an opportunity and can more positively embrace and engage in a new business activity. Moreover, past success in creating new ventures can help an entrepreneur build self-confidence and become less risk-averse. Findings of this dissertation also revealed negative moderating effect of entrepreneurial experience on the relationship between opportunity attributes and opportunity attractiveness among both groups of entrepreneurs as follows: a negative moderating effect on three of the four attributes - i.e. resourcerelatedness, novelty, and perceived future demand - for the independent group and a negative moderating effect on two of the four opportunity attributes - i.e. resourcerelatedness and entry scale - for the corporate group. Therefore, experienced entrepreneurs in both groups appeared to attach a lower weight to certain opportunity attributes when deciding to pursue an opportunity. In a sense, entrepreneurial experience can be a double-edged sword, at least for an independent entrepreneur. Whereas experienced independent entrepreneurs are more willing than novice independent entrepreneurs to pursue new business ideas, their assessments can be prone to miscalculations and misjudgments, perhaps due to overconfidence. Another interesting finding is about the differing nature of impact entrepreneurial experience has among 
independent and corporate entrepreneurs. Whereas the strongest negative effects of entrepreneurial experience for the independent group were found for uncertainty-focused attributes - i.e. novelty and perceived future demand - the negative moderating effect for the corporate group was significant for resource-centered attributes - i.e. resourcerelatedness and entry scale. A possible interpretation is that whereas experienced independent entrepreneurs would still conceive of resource-focused attributes of an opportunity as central and critical, experienced corporate entrepreneurs would have this conception about uncertainty-focused attributes.

\section{Entrepreneurial self-efficacy}

Entrepreneurial self-efficacy reflects an individual's belief in his/her ability to successfully create and manage a new business (Chen et al., 1998). Whereas results of this study revealed no significant direct effect of entrepreneurial self-efficacy on pursuit of an opportunity among either group of entrepreneurs, the findings of the post-hoc analysis demonstrated a positive moderating effect (although marginally significant) of self-efficacy on the relationship between scale of entry and opportunity attractiveness among corporate entrepreneurs. This means that corporate entrepreneurs who are high in self-efficacy, are more likely to pursue large-scale opportunities. Large-scale projects are usually hard to get approved in an organization because they necessitate huge resource commitments. Intrapreneurs who wish to pursue such projects face a serious challenge in convincing top managers and organizational stakeholders of the feasibility and the potential for a considerable return on investment for such opportunities. Perhaps, corporate entrepreneurs who are high in self-efficacy are more confident of their ability 
to initiate such projects and therefore, are less concerned about getting the necessary approvals from top layers of management.

\section{Environmental conditions and opportunity attractiveness}

Apart from individual differences and opportunity attributes, conditions in the external environment also can impact the way entrepreneurs make decisions with regard to pursuing opportunities. For example, in a turbulent environment, opportunities are short-lived and the increased uncertainty requires decision-makers to process greater amounts of information (Haleblian \& Finkelstein, 1993). On the other hand, a munificent environments can compensate for entrepreneurial decision-making mistakes through greater environmental capacity and increased overall growth (Shepherd et al., 2013). In this dissertation, the effect of two important environmental conditions - i.e. dynamism and munificence - on entrepreneurial decision-making was explored. Results, however, revealed a significant effect only for munificence. Below, this effect is discussed.

\section{Industry munificence}

Industry munificence explains the availability of resources necessary for growth of firms in a market (Aldrich, 2008; Dess \& Beard, 1984). In munificent environments, firms can better thwart external threats and create slack resources (Nielsen \& Nielsen, 2013). On the contrary, resource-scarce environments hold little capacity for profitable opportunities due to intense competition over a limited set of resources (Aldrich, 2008; Covin \& Slevin, 1989). Therefore, entrepreneurs are expected to more freely and more confidently pursue new venture ideas in munificent industries as ample external resources make entrepreneurs less concerned about internal resource constraints or limits on resource usage. Results of this dissertation provided strong evidence for the positive effect of industry munificence 
on assessment of an opportunity among both groups of entrepreneurs. First, munificence was shown to have a strong positive effect on the relationship between all four opportunity attributes and opportunity attractiveness among corporate entrepreneurs. In other words, corporate entrepreneurs had significantly more positive evaluations of all opportunity attributes in a munificent industry. Second, munificence was shown to positively moderate the impact resource-relatedness and novelty had on perceived attractiveness of an opportunity among independent entrepreneurs. Therefore, independent entrepreneurs were more likely to pursue resource-related and novel opportunities in munificent industries. Based on the number of attribute effects moderated, one can reason that industry munificence is a more critical criterion in assessing an opportunity for corporate entrepreneurs than for independent entrepreneurs. This means that the moderating effect of munificence is present for a wider range of opportunity attributes among corporate entrepreneurs. Prior research bears some witness to this finding. For example, a study by Sahaym, Steensma, and Barden (2010) shows that, at the industry level, munificent industries provide more opportunities for investment in corporate venturing activities than do industries with stable growth rates. It has also been shown that resource abundance in an industry reduces organization inertia and increases competition among incumbent firms, resulting in innovation races and discovery and exploitation of new opportunities (Aldrich, 1999; Hambrick \& Finkelstein, 1987; Smit \& Trigeorgis, 2012). On the other hand, in less munificent environments with limited sales growth, firms compete over scarce resources and struggle for survival (Castrogiovanni, 1991) and are focused mostly on maintaining stability and legitimacy rather than investing in new opportunities (Hannan \& Freeman, 1989; Khandwalla, 1973). Therefore, environmental munificence hugely impacts decision- 
making in an established firm with regard to pursuing corporate venturing opportunities. I stated earlier that environmental munificence moderated effects of fewer opportunity attributes among independent entrepreneurs. This is, perhaps, because independent entrepreneurs do not yet have a turf to protect, have not established legitimacy, and have not yet fully entered the competition with incumbents and, as such, would not be as equally affected by munificence as would be entrepreneurs in established firms.

It is worth mentioning that among the moderating effects of munificence on decisions of corporate entrepreneurs, the effect on pursuit of a novel opportunity was the greatest. In pursuing a highly novel opportunity, corporate entrepreneurs appear to critically assess the availability of abundant resources in the environment. One explanation would be that organizational decision-makers are typically reluctant to deviate from the

planned, strategic direction of the organization to implement a novel opportunity and abundance of external resources and sales growth in an industry could become the key incentive in such circumstances.

\section{Implications}

\section{Theoretical implications}

In this dissertation, I have explored decision-making in entrepreneurship from an “entrepreneurial cognition” perspective. According to Mitchell et al. (2002), "entrepreneurial cognitions are the knowledge structures that people use to make assessments, judgments, or decisions involving opportunity evaluation, venture creation, and growth" (p. 97). In other words, entrepreneurial cognition explains the mental models and the thought patterns entrepreneurs use to create meaningful connections among opportunity-related cues and to make decisions with regard to starting a new business. 
One of the important factors that can affect cognition of entrepreneurs with regard to pursuing opportunities is context. Entrepreneurs basically operate in either a startup or a corporate context. Corporate entrepreneurs (who operate within the context of a large, established firm) and independent entrepreneurs/entrepreneurs have different cognitive roles which result in different cognitions toward opportunities (Corbett \& Hmieleski, 2007) . Whereas past research provides very scarce knowledge on differences in entrepreneurial decision-making in these two contexts, this study strives to provide major contributions in this regard.

A major theoretical implication of this research is that the two perspectives - i.e. resource availability and uncertainty - used to explore opportunity evaluation provide a strong theoretical basis for explaining the similarities and differences in decision-making in corporate and non-corporate contexts. This is because the four opportunity attributes studied (based on these perspectives) all significantly impacted decisions of corporate and independent entrepreneurs in pursuing an opportunity. One of the interesting findings of this study was the similarity between corporate and independent entrepreneurs in evaluating baseline opportunity attributes. As stated earlier, results showed that corporate and independent entrepreneurs exhibited the exact same preference toward the four attributes studied and the differentiating point was the magnitude of effect of these attributes among the two groups. Perhaps entrepreneurs in startups and in corporations have more or less similar perceptions of opportunity attributes in the first place, but corporate entrepreneurs need to receive more positive signals from the environment to reach the same level of aspiration as independent entrepreneurs. The difference in context between a startup and a corporation could also play a major role in shaping the decision- 
making policies of entrepreneurs and intrapreneurs. We know that organizational strategy, structure, culture and values hugely impact the way in which entrepreneurship is adopted and pursued in an organization (Guth \& Ginsberg, 1990; Leifer et al., 2000). More specifically, corporate entrepreneurs have norms for expected behavior that can be at odds with how independent entrepreneurs pursue and exploit opportunities (Corbett \& Hmieleski, 2007). The finding in this dissertation about the relatively lower impact of opportunity attributes on overall willingness of corporate entrepreneurs to pursue an opportunity is indeed attributable to the cautionary policies that prime intrapreneurs/corporate innovators to protect organizational resources and cause them to adopt a prevention focus. In other words, corporate entrepreneurs need to receive stronger signals about the promise of an opportunity before deciding to further pursue it. On the other hand, the context of a startup poses fewer constraints on exploring new opportunities (Corbett \& Hmieleski, 2007; Morris et al., 2010).

Another theoretical implication of this dissertation is about the effect of entrepreneurial experience on perceptions of opportunities. As entrepreneurs become more experienced and found more new ventures, they appear to put less emphasis on certain opportunity attributes, depending on context. Whereas entrepreneurial experience was shown to cause independent entrepreneurs to put less emphasis on uncertaintyfocused attributes - i.e. knowledge of demand and novelty, it was shown to make corporate entrepreneurs put less emphasis on resource-focused attributes - i.e. resourcerelatedness and entry scale. Perhaps experienced entrepreneurs in each context tend to focus on those opportunity attributes that require more thorough assessments and are more conducive to a successful implementation of an idea vis-à-vis the circumstances in 
that context. Or, it could be that experienced entrepreneurs in each context have become adept at dealing with certain features or requirements of a new business to the extent that these entrepreneurs might fall into the trap of underestimating or undermining the importance of those features in future opportunities.

\section{Practical implications}

A practical implication of this study is about the tradeoffs entrepreneurs make while assessing multiple features of an opportunity. As was shown earlier, the attractiveness of an opportunity depended on the interacting effect attributes had with one another. In a sense, entrepreneurs evaluate attributes of an opportunity as a whole package and varying levels of one attribute can affect favorability of others. For example, novelty was shown to impact favorability of other opportunity attributes among independent entrepreneurs. Therefore, novelty might be an attribute worth considering alongside other features as independent entrepreneurs decide to pursue a new venture idea. In general, inter-relatedness among opportunity attributes implies that entrepreneurs need to make wise tradeoffs when deciding to pursue opportunities and failure to consider a pivotal attribute could result in a less informed decision and incorrect judgement about the desirability of an opportunity.

Another practical implication of this dissertation is that entrepreneurs can improve their decision-making skills by being aware of the array of factors - i.e. opportunity attributes, individual characteristics and dispositions, and environmental conditions - that jointly determine the feasibility and desirability of an opportunity. The more comprehensive and the more relevant decision criteria entrepreneurs use while assessing an opportunity, the more accurately they can form judgements about future outcomes. In 
a sense, this study suggests that corporate and independent entrepreneurs need to be cognizant of the way they make decisions and of the decision criteria that significantly impact opportunity attractiveness in their respective contexts (corporate vs. startup). This higher-order thinking about decisions highlights the importance of "metacognitive" abilities in entrepreneurial decision-making. Metacognition refers to an individual's ability to comprehend, control, and reflect upon his/her learning (Schraw \& Dennison, 1994). Not only metacognition has been recognized as the cognitive basis for “entrepreneurial mindset” (Haynie, Shepherd, Mosakowski, \& Earley, 2009), it has also been known to help decision-makers imagine multiple views of a problem, compare different alternatives, and get feedback to improve future decisions (Haynie et al., 2012). In this regard, corporate and independent entrepreneurs need to improve their metacognitive abilities to be able to incorporate the most relevant pieces of information into their decisions and to be aware of the biases (such as overconfidence) that can deteriorate the accuracy of their assessments.

The insights from this dissertation can also be used to help aspiring entrepreneurs decide which entrepreneurship track (corporate or startup) would best fit their tendencies and proclivities. For instance, I earlier discussed that environmental munificence played a more central role in shaping opportunity-related decisions of corporate entrepreneurs (than those of independent entrepreneurs). Therefore, aspiring entrepreneurs who decide to pursue an entrepreneurship career in a corporate context should expect corporate managers to resist ideas that are to be implemented in resource-scarce industries. Moreover, established organizations are usually more concerned with maintain stability and control and are reluctant to invest organizational assets in uncertain projects. 
However, the context of a startup provides more discretion and flexibility for visionary entrepreneurs in pursuing risky paths (Corbett \& Hmieleski, 2007; Morris et al., 2010). This was indeed manifested in the relatively stronger impact of opportunity attributes on perceptions of opportunity attractiveness among independent entrepreneurs. Therefore, entrepreneurs in large organizations might have to provide stronger evidences to the top management in order to get the necessary approval and support for their new venture ideas.

\section{Limitations and Future Research}

One of the limitations of this dissertation is the limited number of opportunity attributes studied - i.e. four attributes. First, it should be noted that the attributes studied in this dissertation were selected based on major differences between corporate and noncorporate entrepreneurship and were shown to explain similarities, as well as important differences in decision-making between the two groups. Second, increased number of attributes in a conjoint experiment would result in increased number of opportunity scenarios, which would make the assessment task tedious and diminish response reliability. Nevertheless, future studies can incorporate other opportunity attributes to compare entrepreneurial decision-making between corporate and non-corporate contexts. These attributes could be selected with reference to either the same perspectives - i.e. resource availability and uncertainty - or other perspectives salient in explaining variations in opportunity evaluation between the two groups (such as decision-making autonomy, expected reward, and stakeholder support).

Another limitation of this dissertation is a limitation inherent to a conjoint experiment. What a conjoint experiment cannot inform us about is whether a 
variable/attribute is actually relevant for consumers/respondents and is, therefore, effectively processed (Vidal et al., 2013). Whereas conjoint experiment results reveal the part-worths or importance weights respondents attach to different attributes, it is the researcher (not the respondent) who selects the set of attributes to be evaluated.

Therefore, respondents' assessment tasks are limited in scope by the researcher's choice of attributes and might dramatically change in the presence of other attributes of the focal product. The design of the conjoint experiment in this dissertation might also be prone to this potential flaw. A measure I took in my dissertation to minimize this issue was to ensure content validity of the opportunity attributes. As stated earlier, the selection of the opportunity attributes in this dissertation is theoretically justified as it is based on two perspectives that explain a great amount of variance in decision-making in corporate and non-corporate contexts: resource availability and tolerance for uncertainty. Nevertheless, future studies can benefit from a group of expert entrepreneurs' initial screening of opportunity attributes to maximize relevance.

In my dissertation, I used a sample of entrepreneurs operating in the United States. Aside from the challenges in collecting responses from multiple countries, this approach helped me control for unobservable effects arising from differing contexts in which the respondents evaluate the opportunity scenarios (Shepherd \& Zacharakis, 1997). Constraining the business environment to that of the United States was one of the measures I took to create a common context for all the respondents in this study. However, the results of this dissertation might not hold true in other business environments/other countries. Results from studies conducted outside the United States can complement the insights and implications proposed in this dissertation. 


\section{Conclusion}

This dissertation is a first attempt at theorizing and empirically testing the similarities and differences in opportunity evaluation between corporate entrepreneurs and independent entrepreneurs. The merit of this study lies in the fact that although entrepreneurship generally takes place in either a startup or an established firm's context, very limited research has been conducted to this date to explain the cognitive similarities and differences in decision-making in the two settings. Findings of my dissertation increase our knowledge about intricacies and tradeoffs in entrepreneurial decisionmaking in corporate and non-corporate contexts. This dissertation uses three major categories to compare and contrast decision-making in the two contexts: Opportunity attributes, individual differences, and environmental conditions.

By capturing decision policies of entrepreneurs using a conjoint experimental design, I provide evidence that the four opportunity attributes of focus - i.e. knowledge of customer demand, resource-relatedness, novelty, and entry scale - play a significant role in opportunity-related decision-making among corporate and independent entrepreneurs. More specifically, I show that corporate and independent entrepreneurs have similar preferences toward the four opportunity attributes but independent entrepreneurs relatively attach more weight to each attribute. I also provide evidence that entrepreneurs make tradeoffs among opportunity attributes and certain attributes, such as novelty, become a reference point for assessing other attributes.

I also provide evidence for the effect of individual differences on evaluation of opportunities. I demonstrate that being male positively affects an independent entrepreneur's willingness to act upon a new venture idea. I also show that experienced 
corporate and independent entrepreneurs tend to have different focuses on opportunity attributes, compared with their less experienced counterparts. Whereas entrepreneurial experience was shown to make independent entrepreneurs put less emphasis on uncertainty-focused attributes - i.e. knowledge of demand and novelty, it was shown to make corporate entrepreneurs put less emphasis on resource-focused attributes - i.e. resource-relatedness and entry scale. I also demonstrated that entrepreneurial selfefficacy positively moderated corporate entrepreneurs' decision in pursuing a large-scale opportunity.

Finally, I provide evidence to the salience of environmental conditions in shaping cognitions of entrepreneurs in the two contexts. I demonstrate that industry munificence positively impacts perceptions of an opportunity among corporate and independent entrepreneurs and that this impact covers a broader range of opportunities among the corporate group. 


\section{REFERENCES}

Aldrich, H. (1999). Organizations evolving: Sage.

Aldrich, H. (2008). Organizations and environments: Stanford University Press.

Alpert, M., \& Raiffa, H. (1982). A progress report on the training of probability assessors. Reprinted in D. Kahneman, P. Slovic, and A. Tversky (eds.) Judgement under Uncertainty: Heuristics and Biases: Cambridge: Cambridge University Press.

Amabile, T. M. (1997). Entrepreneurial creativity through motivational synergy. The Journal of Creative Behavior, 31(1), 18-26.

Amason, A. C., Shrader, R. C., \& Tompson, G. H. (2006). Newness and novelty: Relating top management team composition to new venture performance. Journal of Business Venturing, 21(1), 125-148.

Artinger, S., \& Powell, T. C. (2016). Entrepreneurial failure: Statistical and psychological explanations. Strategic management journal, 37(6), 1047-1064.

Autio, E., Dahlander, L., \& Frederiksen, L. (2013). Information exposure, opportunity evaluation, and entrepreneurial action: An investigation of an online user community. Academy of Management Journal, 56(5), 1348-1371.

Baker, T., Gedajlovic, E., \& Lubatkin, M. (2005). A framework for comparing entrepreneurship processes across nations. Journal of International Business Studies, 36(5), 492-504.

Baker, T., \& Nelson, R. E. (2005). Creating something from nothing: Resource construction through entrepreneurial bricolage. Administrative science quarterly, 50(3), 329-366.

Barney, J. (1991). Firm resources and sustained competitive advantage. Journal of management, 17(1), 99-120.

Barney, J. B. (2014). Gaining and sustaining competitive advantage: Pearson higher ed. 
Baron, R. A., \& Ensley, M. D. (2006). Opportunity recognition as the detection of meaningful patterns: Evidence from comparisons of novice and experienced entrepreneurs. Management science, 52(9), 1331-1344.

Barringer, B. R., \& Bluedorn, A. C. (1999). The relationship between corporate entrepreneurship and strategic management. Strategic management journal, 421444.

Baumol, W. J. (1996). Entrepreneurship: Productive, unproductive, and destructive. Journal of Business Venturing, 11(1), 3-22.

Bhidé, A. V. (2003). The origin and evolution of new businesses: Oxford University Press.

Biggadike, R. (1989). The risky business of diversification Readings in Strategic Management (pp. 177-190): Springer.

Bryant, P. (2007). Self-regulation and decision heuristics in entrepreneurial opportunity evaluation and exploitation. Management Decision, 45(4), 732-748.

Burgelman, R. A. (1991). Intraorganizational ecology of strategy making and organizational adaptation: Theory and field research. Organization science, 2(3), 239-262.

Burns, T. E., \& Stalker, G. M. (1961). The management of innovation. London: Tavistock, 1961.

Busenitz, L. W., \& Barney, J. B. (1997). Differences between entrepreneurs and managers in large organizations: Biases and heuristics in strategic decisionmaking. Journal of Business Venturing, 12(1), 9-30.

Cantillon, R. (1755). Essay on the nature of general commerce. Henry Higgs, trans. London: Macmllan.

Carroll, G. R., \& Hannan, M. T. (1989). Density delay in the evolution of organizational populations: A model and five empirical tests. Administrative science quarterly, 411-430.

Casson, M. (1982). The entrepreneur: An economic theory: Rowman \& Littlefield.

Casson, M., \& Wadeson, N. (2007). The discovery of opportunities: Extending the economic theory of the entrepreneur. Small Business Economics, 28(4), 285-300.

Castrogiovanni, G. J. (1991). Environmental munihcence; a theoretical assessment. Academy of Management Review, 16(3), 542-565. 
Cheah, H.-B. (1990). Schumpeterian and Austrian entrepreneurship: Unity within duality. Journal of Business Venturing, 5(6), 341-347.

Chen, C. C., Greene, P. G., \& Crick, A. (1998). Does entrepreneurial self-efficacy distinguish entrepreneurs from managers? Journal of Business Venturing, 13(4), 295-316.

Choi, Y. R., \& Phan, P. H. (2006). The influences of economic and technology policy on the dynamics of new firm formation. Small Business Economics, 26(5), 493-503.

Choi, Y. R., \& Shepherd, D. A. (2004). Entrepreneurs' decisions to exploit opportunities. Journal of management, 30(3), 377-395.

Clogg, C. C., Petkova, E., \& Haritou, A. (1995). Statistical methods for comparing regression coefficients between models. American Journal of Sociology, 100(5), 1261-1293.

Cohen, J. (2013). Statistical power analysis for the behavioral sciences: Routledge.

Combs, J. G., Ketchen Jr, D. J., Ireland, R. D., \& Webb, J. W. (2011). The role of resource flexibility in leveraging strategic resources. Journal of Management studies, 48(5), 1098-1125.

Cooper, A. C., Willard, G. E., \& Woo, C. Y. (1986). Strategies of high performing new and small firms: A reexamination of the niche concept. Journal of Business Venturing, 1(3), 247-260.

Corbett, A. C. (2005). Experiential learning within the process of opportunity identification and exploitation. Entrepreneurship Theory and Practice, 29(4), $473-491$.

Corbett, A. C., \& Hmieleski, K. M. (2007). The conflicting cognitions of corporate entrepreneurs. Entrepreneurship Theory and Practice, 31(1), 103-121.

Covin, J. G., \& Slevin, D. P. (1988). The influence of organization structure on the utility of an entrepreneurial top management style. Journal of Management studies, 25(3), 217-234.

Covin, J. G., \& Slevin, D. P. (1989). Strategic management of small firms in hostile and benign environments. Strategic management journal, 10(1), 75-87.

Crane, F. G. (2012). Marketing for entrepreneurs: Concepts and applications for new ventures: Sage Publications.

Davidsson, P., Delmar, F., \& Wiklund, J. (2006). Entrepreneurship and the Growth of Firms: Edward Elgar Publishing. 
Davidsson, P., \& Honig, B. (2003). The role of social and human capital among nascent entrepreneurs. Journal of Business Venturing, 18(3), 301-331.

De Carolis, D. M., \& Saparito, P. (2006). Social capital, cognition, and entrepreneurial opportunities: A theoretical framework. Entrepreneurship Theory and Practice, $30(1), 41-56$.

Dess, G. G., \& Beard, D. W. (1984). Dimensions of organizational task environments. Administrative science quarterly, 52-73.

Dewald, J., \& Bowen, F. (2010). Storm clouds and silver linings: Responding to disruptive innovations through cognitive resilience. Entrepreneurship Theory and Practice, 34(1), 197-218.

Diggle, P., Liang, K.Y., \& Zeger, S. L. (1994). Longitudinal data analysis. New York: Oxford University Press, 5, 13.

Dimov, D. (2010). Nascent entrepreneurs and venture emergence: Opportunity confidence, human capital, and early planning. Journal of Management studies, 47(6), 1123-1153.

Fadol, Y., Barhem, B., \& Elbanna, S. (2015). The mediating role of the extensiveness of strategic planning on the relationship between slack resources and organizational performance. Management Decision, 53(5), 1023-1044.

Fan, T. P. C. (2010). De novo venture strategy: arch incumbency at inaugural entry. Strategic management journal, 31(1), 19-38.

Fiet, J. O. (1996). The informational basis of entrepreneurial discovery. Small Business Economics, 8(6), 419-430.

Fischhoff, B., Slovic, P., \& Lichtenstein, S. (1977). Knowing with certainty: The appropriateness of extreme confidence. Journal of Experimental Psychology: Human perception and performance, 3(4), 552.

Fleming, L. (2001). Recombinant uncertainty in technological search. Management science, 47(1), 117-132.

Forbes, D. P. (2005). Are some entrepreneurs more overconfident than others? Journal of Business Venturing, 20(5), 623-640.

Gaglio, C. M., \& Katz, J. A. (2001). The psychological basis of opportunity identification: Entrepreneurial alertness. Small Business Economics, 16(2), 95111. 
Garcia, R., \& Calantone, R. (2002). A critical look at technological innovation typology and innovativeness terminology: a literature review. Journal of product innovation management, 19(2), 110-132.

Garrett, R. P., \& Holland, D. V. (2015). Environmental effects on the cognitions of corporate and independent entrepreneurs. Small Business Economics, 45(2), 369381.

Gartner, W. B. (1988). "Who is an entrepreneur?" is the wrong question. American journal of small business, 12(4), 11-32.

George, G. (2005). Slack resources and the performance of privately held firms. Academy of Management Journal, 48(4), 661-676.

Gilad, B., Kaish, S., \& Loeb, P. D. (1987). Cognitive dissonance and utility maximization: A general framework. Journal of Economic Behavior \& Organization, 8(1), 61-73.

Glick, W. H., Huber, G. P., Miller, C. C., Doty, D. H., \& Sutcliffe, K. M. (1990). Studying changes in organizational design and effectiveness: Retrospective event histories and periodic assessments. Organization Science, 1(3), 293-312.

Goll, I., \& Rasheed, A. M. (1997). Rational decision-making and firm performance: the moderating role of the environment. Strategic management journal, 18(7), 583591.

Green, P. E., Krieger, A. M., \& Wind, Y. (2001). Thirty years of conjoint analysis: Reflections and prospects. Interfaces, 31(3_supplement), S56-S73.

Green, P. E., \& Srinivasan, V. (1990). Conjoint analysis in marketing: new developments with implications for research and practice. The journal of marketing, 3-19.

Grichnik, D., Smeja, A., \& Welpe, I. (2010). The importance of being emotional: How do emotions affect entrepreneurial opportunity evaluation and exploitation? Journal of Economic Behavior \& Organization, 76(1), 15-29.

Gupta, V. K., Goktan, A. B., \& Gunay, G. (2014). Gender differences in evaluation of new business opportunity: A stereotype threat perspective. Journal of Business Venturing, 29(2), 273-288.

Guth, W. D., \& Ginsberg, A. (1990). Guest editors' introduction: Corporate entrepreneurship. Strategic management journal, 5-15.

Hahn, G. J., \& Shapiro, S. S. (1966). A cataloging and computer program for the design and analysis of orthogonal symmetric and asymmetric fractional factorial experiments: General Electric Research and Development Center. 
Haleblian, J., \& Finkelstein, S. (1993). Top management team size, CEO dominance, and firm performance: The moderating roles of environmental turbulence and discretion. Academy of Management Journal, 36(4), 844-863.

Hambrick, D. C., \& Finkelstein, S. (1987). Managerial discretion: A bridge between polar views of organizational outcomes. Research in organizational behavior.

Hannan, M. T., \& Freeman, J. (1984). Structural inertia and organizational change. American sociological review, 149-164.

Hannan, M. T., \& Freeman, J. (1989). Organizational ecology: Harvard university press.

Hastie, R. (2001). Problems for judgment and decision making. Annual review of psychology, 52(1), 653-683.

Hayek, F. A. (1945). The use of knowledge in society. The American economic review, 35(4), 519-530.

Haynie, J., Shepherd, D., Mosakowski, E., \& Earley, C. (2009). Cognitive adaptability: The theoretical origins of the entrepreneurial mindset. Journal of Business Venturing, 25(2), 217-229.

Haynie, J. M., Shepherd, D. A., \& McMullen, J. S. (2009). An opportunity for me? The role of resources in opportunity evaluation decisions. Journal of Management studies, 46(3), 337-361.

Haynie, J. M., Shepherd, D. A., \& Patzelt, H. (2012). Cognitive adaptability and an entrepreneurial task: The role of metacognitive ability and feedback. Entrepreneurship Theory and Practice, 36(2), 237-265.

Hayton, J. C., \& Cholakova, M. (2012). The role of affect in the creation and intentional pursuit of entrepreneurial ideas. Entrepreneurship Theory and Practice, 36(1), 4168.

Hayward, M. L., Shepherd, D. A., \& Griffin, D. (2006). A hubris theory of entrepreneurship. Management science, 52(2), 160-172.

Hébert, R. F., \& Link, A. N. (1988). The entrepreneur: mainstream views \& radical critiques: Praeger Publishers.

Helfat, C. E., \& Raubitschek, R. S. (2000). Product sequencing: co-evolution of knowledge, capabilities and products. Strategic management journal, 961-979.

Higgins, E. T., Friedman, R. S., Harlow, R. E., Idson, L. C., Ayduk, O. N., \& Taylor, A. (2001). Achievement orientations from subjective histories of success: Promotion pride versus prevention pride. European Journal of Social Psychology, 31(1), 323. 
Hmieleski, K. M., \& Baron, R. A. (2008). Regulatory focus and new venture performance: A study of entrepreneurial opportunity exploitation under conditions of risk versus uncertainty. Strategic Entrepreneurship Journal, 2(4), 285-299.

Hmieleski, K. M., \& Baron, R. A. (2009). Entrepreneurs' optimism and new venture performance: A social cognitive perspective. Academy of Management Journal, 52(3), 473-488.

Hobson, E. L., \& Morrison, R. M. (1983). How do corporate start-up ventures fare. Frontiers of entrepreneurship research, 390-410.

Holland, D. V., \& Shepherd, D. A. (2013). Deciding to persist: Adversity, values, and entrepreneurs' decision policies. Entrepreneurship Theory and Practice, 37(2), $331-358$

Hough, J. R., \& White, M. A. (2003). Environmental dynamism and strategic decisionmaking rationality: an examination at the decision level. Strategic management journal, 24(5), 481-489.

Hsu, D. H. (2004). What do entrepreneurs pay for venture capital affiliation? The Journal of Finance, 59(4), 1805-1844.

Keh, H. T., Foo, M. D., \& Lim, B. C. (2002). Opportunity evaluation under risky conditions: The cognitive processes of entrepreneurs. Entrepreneurship Theory and Practice, 27(2), 125-148.

Khandwalla, P. N. (1973). Viable and effective organizational designs of firms. Academy of Management Journal, 16(3), 481-495.

Klavans, R., Shanley, M., \& Evan, W. M. (1985). The Management of Internal CorporateVentures-Entrepreneurship and Innovation. Columbia Journal of World Business, 20(2), 21-27.

Knight, F. H. (1921). Risk, uncertainty and profit. New York: Hart, Schaffner and Marx.

Krueger Jr, N. F., Reilly, M. D., \& Carsrud, A. L. (2000). Competing models of entrepreneurial intentions. Journal of Business Venturing, 15(5-6), 411-432.

Krueger, N. (1993). The impact of prior entrepreneurial exposure on perceptions of new venture feasibility and desirability. Entrepreneurship theory and practice, 18(1), 5-21.

Krueger, N., \& Dickson, P. R. (1994). How believing in ourselves increases risk taking: Perceived self-efficacy and opportunity recognition. Decision Sciences, 25(3), 385-400. 
Lee, J.-H., \& Venkataraman, S. (2006). Aspirations, market offerings, and the pursuit of entrepreneurial opportunities. Journal of Business Venturing, 21(1), 107-123.

Leifer, R., McDermott, C. M., O'connor, G. C., Peters, L. S., Rice, M. P., \& Veryzer Jr, R. W. (2000). Radical innovation: How mature companies can outsmart upstarts: Harvard Business Press.

Lohrke, F. T., Holloway, B. B., \& Woolley, T. W. (2010). Conjoint analysis in entrepreneurship research: A review and research agenda. Organizational Research Methods, 13(1), 16-30.

Low, M. B., \& MacMillan, I. C. (1988). Entrepreneurship: Past research and future challenges. Journal of management, 14(2), 139-161.

Lumpkin, G. T., \& Dess, G. G. (1996). Clarifying the entrepreneurial orientation construct and linking it to performance. Academy of Management Review, 21(1), 135-172.

Lumpkin, G. T., \& Dess, G. G. (2001). Linking two dimensions of entrepreneurial orientation to firm performance: The moderating role of environment and industry life cycle. Journal of Business Venturing, 16(5), 429-451.

MacMillan, I. C., Block, Z., \& Narasimha, P. S. (1986). Corporate venturing: Alternatives, obstacles encountered, and experience effects. Journal of Business Venturing, 1(2), 177-191.

MacMillan, I. C., \& Day, D. L. (1987). Corporate ventures into industrial markets: Dynamics of aggressive entry. Journal of Business Venturing, 2(1), 29-39.

Markides, C. C., \& Geroski, P. A. (2004). Fast second: How smart companies bypass radical innovation to enter and dominate new markets (Vol. 325): John Wiley \& Sons.

Markman, G. D., Balkin, D. B., \& Baron, R. A. (2002). Inventors and new venture formation: the effects of general self-efficacy and regretful thinking. Entrepreneurship Theory and Practice, 27(2), 149-165.

Martiarena, A. (2013). What's so entrepreneurial about intrapreneurs? Small Business Economics, 40(1), 27-39.

McDougall, P. P. (1989). International versus domestic entrepreneurship: new venture strategic behavior and industry structure. Journal of Business Venturing, 4(6), 387-400. 
McKelvie, A., Haynie, J. M., \& Gustavsson, V. (2011). Unpacking the uncertainty construct: Implications for entrepreneurial action. Journal of Business Venturing, 26(3), 273-292.

McMullen, J. S., \& Shepherd, D. A. (2006). Entrepreneurial action and the role of uncertainty in the theory of the entrepreneur. Academy of Management Review, $31(1), 132-152$.

Miles, R. E., \& Snow, C. (1978). CC [1978]: Organizational strategy, structure and process. Now York: McGraw-Hill.

Miller, A., \& Camp, B. (1985). Exploring determinants of success in corporate ventures. Journal of Business Venturing, 1(1), 87-105.

Miller, D. (1983). The correlates of entrepreneurship in three types of firms. Management science, 29(7), 770-791.

Miller, D., \& Friesen, P. H. (1982). Innovation in conservative and entrepreneurial firms: Two models of strategic momentum. Strategic management journal, 3(1), 1-25.

Miller, D., \& Friesen, P. H. (1984). A longitudinal study of the corporate life cycle. Management science, 30(10), 1161-1183.

Min, S., Kalwani, M. U., \& Robinson, W. T. (2006). Market pioneer and early follower survival risks: A contingency analysis of really new versus incrementally new product-markets. Journal of Marketing, 70(1), 15-33.

Mitchell, J. R., \& Shepherd, D. A. (2010). To thine own self be true: Images of self, images of opportunity, and entrepreneurial action. Journal of Business Venturing, 25(1), 138-154.

Mitchell, R. K., Busenitz, L., Lant, T., McDougall, P. P., Morse, E. A., \& Smith, J. B. (2002). Toward a theory of entrepreneurial cognition: Rethinking the people side of entrepreneurship research. Entrepreneurship Theory and Practice, 27(2), 93104.

Morris, M. H., Kuratko, D. F., \& Covin, J. G. (2010). Corporate entrepreneurship \& innovation: Cengage Learning.

Neck, C. P., \& Manz, C. C. (1992). Thought self-leadership: The influence of self-talk and mental imagery on performance. Journal of Organizational Behavior, 13(7), 681-699.

Nielsen, B. B., \& Nielsen, S. (2013). Top management team nationality diversity and firm performance: A multilevel study. Strategic management journal, 34(3), 373382. 
Palich, L. E., \& Bagby, D. R. (1995). Using cognitive theory to explain entrepreneurial risk-taking: Challenging conventional wisdom. Journal of Business Venturing, 10(6), 425-438.

Patterson, M. L., \& Lightman, S. (1993). Accelerating innovation: improving the process of product development: Van Nostrand Reinhold Company.

Penrose, E. (1959). The theory of the firm. NY: John Wiley \& Sons.

Robinson, A. T., \& Marino, L. D. (2015). Overconfidence and risk perceptions: Do they really matter for venture creation decisions? International Entrepreneurship and Management Journal, 11(1), 149-168.

Rodríguez-Pinto, J., Gutiérrez-Cillán, J., \& Rodríguez-Escudero, A. I. (2007). Order and scale of market entry, firm resources, and performance. European Journal of Marketing.

Sahaym, A., Steensma, H. K., \& Barden, J. Q. (2010). The influence of R\&D investment on the use of corporate venture capital: An industry-level analysis. Journal of Business Venturing, 25(4), 376-388.

Salge, T. O. (2012). The temporal trajectories of innovative search: insights from public hospital services. Research Policy, 41(4), 720-733.

Schraw, G., \& Dennison, R. S. (1994). Assessing metacognitive awareness. Contemporary educational psychology, 19(4), 460-475.

Schumpeter, J. A. (1934). The schumpttr: Theory economic development: Harvard University Press.

Shane, S., \& Stuart, T. (2002). Organizational endowments and the performance of university start-ups. Management science, 48(1), 154-170.

Shane, S., \& Venkataraman, S. (2000). The promise of entrepreneurship as a field of research. Academy of Management Review, 25(1), 217-226.

Shapero, A. (1975). The displaced, uncomfortable entrepreneur. Psychology Today, 9(6), 83-88.

Shapero, A., \& Sokol, L. (1982). The social dimensions of entrepreneurship. In C. A. Kent, D. L. Sexton, \& K. H. Ves- per (Eds.), Encylclopedia of entrepreneurship (pp. 72-90). Englewood Cliffs, NJ: Prentice-Hall.

Sharma, P., \& Chrisman, S. J. J. (2007). Toward a reconciliation of the definitional issues in the field of corporate entrepreneurship (pp. 83-103): Springer. 
Shepherd, D. A. (1999). Venture capitalists' assessment of new venture survival. Management science, 45(5), 621-632.

Shepherd, D. A., Patzelt, H., \& Baron, R. A. (2013). "I care about nature, but...”: Disengaging values in assessing opportunities that cause harm. Academy of Management Journal, 56(5), 1251-1273.

Shepherd, D. A., \& Zacharakis, A. (1997). Conjoint analysis: A window of opportunity for entrepreneurship research. Advances in entrepreneurship, firm emergence and growth, 3, 203-248.

Shrader, R. C., \& Simon, M. (1997). Corporate versus independent new ventures: Resource, strategy, and performance differences. Journal of Business Venturing, 12(1), 47-66.

Smit, H. T., \& Trigeorgis, L. (2012). Strategic investment: Real options and games: Princeton University Press.

Smith, K., \& DeGregorio, D. (2002). In press. Bisociation, discovery, and entrepreneurial action. Strategic entrepreneurship: Creating an integrated mindset. Oxford: Blackwell, 97, 102-122.

Stevenson, H. H., \& Carlos Jarrillo-Mossi, J. (1986). Preserving entrepreneurship as companies grow. Journal of business strategy, 7(1), 10-23.

Sutcliffe, K. M. (1994). What executives notice: Accurate perceptions in top management teams. Academy of Management Journal, 37(5), 1360-1378.

Tan, J., \& Peng, M. W. (2003). Organizational slack and firm performance during economic transitions: Two studies from an emerging economy. Strategic management journal, 24(13), 1249-1263.

Taylor, S. E. (1998). The social being in social psychology. In D. Gilbert, S. T. Fiske, \& G. Lindzey (Eds.), Handbook of social psychology (4th ed., Vol. 2, pp.58-95). New York: McGraw Hill.

Thornhill, S., \& Amit, R. (2001). A dynamic perspective of internal fit in corporate venturing. Journal of Business Venturing, 16(1), 25-50.

Tripsas, M. (1997). Unraveling the process of creative destruction: Complementary assets and incumbent survival in the typesetter industry. Strategic management journal, 119-142.

Tsai, W. M.-H., MacMillan, I. C., \& Low, M. B. (1991). Effects of strategy and environment on corporate venture success in industrial markets. Journal of Business Venturing, 6(1), 9-28. 
Tversky, A., \& Kahneman, D. (1974). Judgment under uncertainty: Heuristics and biases. science, 185(4157), 1124-1131.

Ucbasaran, D., Westhead, P., Wright, M., \& Flores, M. (2010). The nature of entrepreneurial experience, business failure and comparative optimism. Journal of Business Venturing, 25(6), 541-555.

Vidal, L., Antúnez, L., Sapolinski, A., Giménez, A., Maiche, A., \& Ares, G. (2013). Can eye-tracking techniques overcome a limitation of conjoint analysis? Case study on healthfulness perception of yogurt labels. Journal of Sensory Studies, 28(5), 370380 .

Von Hippel, E. (1977). Successful and failing internal corporate ventures: An empirical analysis. Industrial Marketing Management, 6(3), 163-174.

Wernerfelt, B. (1984). A resource-based view of the firm. Strategic management journal, 5(2), 171-180.

Wiklund, J., \& Shepherd, D. (2003). Aspiring for, and achieving growth: The moderating role of resources and opportunities. Journal of Management studies, 40(8), 19191941.

Wilson, F., Kickul, J., \& Marlino, D. (2007). Gender, entrepreneurial self-efficacy, and entrepreneurial career intentions: Implications for entrepreneurship education. Entrepreneurship Theory and Practice, 31(3), 387-406.

Woltman, H., Feldstain, A., MacKay, J. C., \& Rocchi, M. (2012). An introduction to hierarchical linear modeling. Tutorials in quantitative methods for psychology, $8(1), 52-69$.

Wood, M. S., McKelvie, A., \& Haynie, J. M. (2014). Making it personal: Opportunity individuation and the shaping of opportunity beliefs. Journal of Business Venturing, 29(2), 252-272.

Wood, M. S., \& Williams, D. W. (2014). Opportunity evaluation as rule-based decision making. Journal of Management studies, 51(4), 573-602.

Wood, R., \& Bandura, A. (1989). Social cognitive theory of organizational management. Academy of Management Review, 14(3), 361-384.

Zahra, S. A. (1991). Predictors and financial outcomes of corporate entrepreneurship: An exploratory study. Journal of Business Venturing, 6(4), 259-285.

Zahra, S. A. (1993). A conceptual model of entrepreneurship as firm behavior: A critique and extension. Entrepreneurship Theory and Practice, 17(4), 5-21. 
Zahra, S. A. (1996). Goverance, ownership, and corporate entrepreneurship: The moderating impact of industry technological opportunities. Academy of Management Journal, 39(6), 1713-1735.

Zeithaml, V. A., \& Bitner, M. J. (1996). Services marketing: McGraw Hill.

Zhao, H., Seibert, S. E., \& Hills, G. E. (2005). The mediating role of self-efficacy in the development of entrepreneurial intentions. Journal of applied psychology, 90(6), 1265 . 
APPENDIX

Survey Questionnaire

\section{Description of Study}

Thank you for agreeing to take part in this survey. The purpose of this study is to better understand how entrepreneurs make opportunity-related decisions.

Your participation in this survey is voluntary. By proceeding, you are indicating your consent for us to use your responses in our study of entrepreneurial decision-making. There are no right or wrong answers to any of the questions asked in this survey, so please feel free to respond candidly. All of your responses will be kept confidential and the information provided will be used solely for the purpose of this research project.

This survey consists of four sections. In section 1, you will answer questions about the industry and the business environment you operate in. In section 2, you will be presented with hypothetical opportunity scenarios and you will be asked to evaluate the attractiveness of each scenario by indicating your willingness to pursue and exploit the proposed opportunity. In section 3, you will answer questions on self-efficacy and selfregulation abilities. In the last section, you will respond to a number of employment, business background, and demographic questions.

Before proceeding to section 1, please indicate if you are an independent entrepreneur or a corporate entrepreneur (intrapreneur) by referring to the following definitions:

\section{Independent Entrepreneur:}

A person who is a founder of a firm and is involved in the management of that firm.

\section{Corporate Entrepreneur:}

An employee who has been involved in the development of new business activities (such as establishing a new outlet or subsidiary, or launching new products and new product-market combinations) for their employer during the last 2 years. The employee's involvement might have been in various forms such as developing and promoting a new business idea, preparing a business plan, developing marketing activities or searching for funding sources. 
What type of entrepreneur are you?

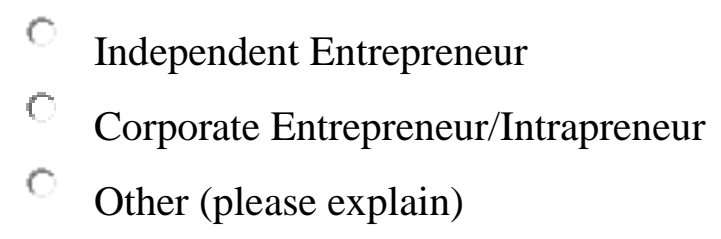

\section{Section 1: Industry and Business Environment}

Please answer the following questions for your principal industry. For every scale, the two statements represent opposite ends of a continuum. Choose the number in each scale that best approximates the actual conditions in it.

\section{Questionnaire 1 (Environmental Dynamism)}

1.

Our firm must rarely change its marketing practices to keep up with the market and competitors

2.

The rate at which products/services are getting obsolete in the industry is very slow

3.

Actions of competitors are quite easy to predict

$\begin{array}{lllllll}1 & 2 & 3 & 4 & 5 & 6 & 7\end{array}$

Our firm must frequently change its marketing practices (e.g. semiannually) to keep up with the market and competitors.
The rate at which products/services are getting obsolete in the industry is very fast. 
4.

Demand and consumer tastes are fairly easy to forecast

$\begin{array}{llllllll}1 & 2 & 3 & 4 & 5 & 6 & 7 & \begin{array}{l}\text { Demand and consumer } \\ \text { tastes are almost } \\ \text { unpredictable }\end{array}\end{array}$

5.

The

production/servic

e technology is

not subject to

$\begin{array}{lllllll}1 & 2 & 3 & 4 & 5 & 6 & 7\end{array}$

The production/service

very much change

technology changes often

and in a major way.

and is well

established

\section{Questionnaire 2 (Industry Munificence)}

How accurate are the following statements:

1. Demand for the products/services of your industry is growing and will continue to grow

Completely

Inaccurate

Somewhat

accurate

4

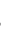

5

Completely accurate

3

6

7

2. The investment or marketing opportunities for firms in your industry are very favorable at the present time

Completely

Inaccurate

1
Somewhat

accurate

4
3

5

6
Completely accurate

7 
3. The opportunities for firms in your industry to expand the scope of their existing products/markets are extremely abundant

Completely

Somewhat

Completely

Inaccurate

accurate

accurate

1

2

3

4

5

6

7

4. Resources for growth and expansions are easily accessible in your industry

Completely

Inaccurate

12
Somewhat

accurate

3
4

5
Completely accurate

7

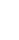

5. In your industry, sales have been growing and are likely to grow

Completely

Inaccurate

1

2

3

Somewhat

accurate

5

6 


\section{Section 2: Opportunity Profiles}

In this section, you will be presented with 25 hypothetical scenarios of entrepreneurial opportunity, each exhibiting a unique combination of opportunity attributes. The opportunity attributes used in this study are Resource Relatedness, Entry Scale, Novelty, and Knowledge of Customer Demand. The following table provides a practical definition of these attributes:

\begin{tabular}{||l||l||}
\hline Resource Relatedness & $\begin{array}{l}\text { The extent to which the resources required to exploit the } \\
\text { opportunity (comprising physical, human capital, and } \\
\text { organizational resources) are already at your/your } \\
\text { organization's disposal or are complementary to your/your } \\
\text { organization's existing resource endowments }\end{array}$ \\
\hline \hline Entry Scale & $\begin{array}{l}\text { Number of geographical markets or the range of customers } \\
\text { that have to be targeted/covered for an efficient entry into } \\
\text { the market }\end{array}$ \\
\hline \hline Novelty & $\begin{array}{l}\text { The extent to which the offered product/service is different } \\
\text { from the existing products/services in the market. }\end{array}$ \\
\hline Knowledge of Customer & $\begin{array}{l}\text { The level of your certainty over future customer demand } \\
\text { for the new product/service. }\end{array}$ \\
\hline
\end{tabular}

Please consider each scenario as a separate situation - independent of all others. While evaluating each opportunity, please assume the following:

- You are judging the viability of creating a new business/venture based on the opportunity described.

- Assess the opportunity as you would in the context of your current industry and business environment (i.e. according to your assessments in section 1 of this survey).

- The opportunity will/can be exploited in the present US economic environment. 


\section{Sample Opportunity Profile [Not shown to respondents]}

Opportunity XYZ

\begin{tabular}{|c|c|c|}
\hline $\begin{array}{l}\text { Opportunity } \\
\text { Attribute }\end{array}$ & Level & Interpretation \\
\hline $\begin{array}{l}\text { Resource } \\
\text { Relatedness }\end{array}$ & $\mathrm{HIGH}$ & $\begin{array}{c}\text { the resources required for exploiting this } \\
\text { opportunity are already at your/organization's } \\
\text { disposal or are complementary to } \\
\text { your/organization's existing resource } \\
\text { endowments }\end{array}$ \\
\hline Entry Scale & LOW & $\begin{array}{l}\text { You will target a specific geographical market or } \\
\text { a limited range of customers. }\end{array}$ \\
\hline Novelty & HIGH & $\begin{array}{l}\text { This opportunity, if exploited, will result in a } \\
\text { product or service that is highly different from the } \\
\text { existing products or services in the market }\end{array}$ \\
\hline $\begin{array}{c}\text { Knowledge of } \\
\text { Customer Demand }\end{array}$ & LOW & $\begin{array}{l}\text { This opportunity, if exploited, will result in a } \\
\text { product or service for which the customer demand } \\
\text { is hardly predictable. }\end{array}$ \\
\hline
\end{tabular}

How likely are you to invest resources in pursuing and exploiting this opportunity?

\begin{tabular}{ccccccccc}
$\begin{array}{c}\text { Very } \\
\text { Unlikely }\end{array}$ & & \multicolumn{3}{c}{$\begin{array}{c}\text { Somewhat } \\
\text { Likely }\end{array}$} \\
1 & 2 & 3 & 4 & 5 & 6 & 7 & 8 & 9
\end{tabular}

Note: A total of 25 opportunity profiles (comprising a warmup scenario, 16 estimation profiles, 5 reliability profiles, and 3 validation profiles) were presented to each respondent. Whereas this document includes only a sample opportunity profile to save space, a separate document includes all 25 opportunity profiles. 


\section{Section 3: Self-efficacy and self-regulation}

\section{Questionnaire 3 (Entrepreneurial Self-efficacy)}

Please indicate how confident you are in your ability to perform the following roles/tasks:

1. Identifying new business opportunities:

Not confident

at all

O
Somewhat

confident

O

O
Completely

confident

O

2. Creating new products:

Not confident

at all

$\mathrm{O}$
$\mathrm{O}$
Somewhat confident

$\mathrm{O}$
Completely confident

O

3. Thinking creatively:

Not confident

at all

O

O
Somewhat confident

O
Completely confident

O

O

4. Commercializing an idea or new development:

Not confident

at all

O
Somewhat

confident
Completely

confident

O

O

O

\section{Questionnaire 4 (Regulatory Focus)}

Please answer the following questions about specific events in your life:

1. Compared to most people, are you typically able to get what you want out of life?

Never or seldom

O
$\mathrm{O}$
Sometimes

$\mathrm{O}$
O
Very often

O 
2. Growing up, would you ever "cross the line" by doing things that your parents would not tolerate?

Never or seldom

Sometimes

Very often

O

0

0

0

0

3. How often did you obey rules and regulations that were established by your parents?

Never or seldom

Sometimes

Very often

O

0

0

0

0

4. Growing up, did you ever act in ways that your parents thought were objectionable?

Never or seldom

Sometimes

Very often

O

O

0

O

O

5. Do you often do well at different things that you try?

Never or seldom

Sometimes

Very often

O

0

O

O

○

6. Not being careful enough has gotten me into trouble at times.

Never or seldom

Sometimes

Very often

O

O

0

O

0

7. When it comes to achieving things that are important to me, I find that I don't perform as well as I ideally would like to do.

Never or seldom

Sometimes

Very often

O

O

O

O

O

8. I feel like I have made progress toward being successful in my life.

Never or seldom

O
Sometimes

O
$\mathrm{O}$
Very often

O
$\mathrm{O}$ 


\section{Section 4: Demographics and employment data}

1. What is your sex?

C Female

C Male

Prefer not to answer

2. What is your ethnicity?

$\begin{array}{ll}\frac{c}{c} & \text { African American } \\ \frac{c}{c} & \text { Asian } \\ \frac{c}{c} & \text { Pispanic } \\ \frac{c}{c} & \text { White } \\ \frac{c}{c} & \text { Other } \\ & \text { Prefer not to answer }\end{array}$

3. How old are you?

$<$ Drop-down list $>$

4. What is you highest education to this date?

Less than high school degree

High school graduate (high school diploma or equivalent including GED)

Some college but no degree

Associate degree in college (2-year)

Bachelor's degree in college (4-year)

C. Master's degree

$\checkmark$ Doctoral degree

Professional grade (MD,JD, etc.)

Other 
5. Which of the following industries most closely matches the one in which you primarily work?

Forestry, fishing, hunting or agriculture support

Real estate or rental and leasing

C Mining

Professional, scientific or technical services

C Utilities

$\checkmark$ Management of companies or enterprises

Construction

Admin, support, waste management or remediation services

C Manufacturing

$\bigcirc$ Educational services

Wholesale trade

Health care or social assistance

Retail trade

$\checkmark$ Arts, entertainment or recreation

Transportation or warehousing

C Accommodation or food services

Information

Other services (except public administration)

$\checkmark$ Finance or insurance

U Unclassified establishments

6. For how many years have you been working in this industry?

$<$ Drop-down list $>$ 
7. What is the name of your organization/firm?

< Open-ended response >

8. What is your current position title?

$<$ Open-ended response >

9. How long has your organization/firm been in business? (in years)

$<$ Drop-down list $>$

10. How many employees work in your organization/firm?

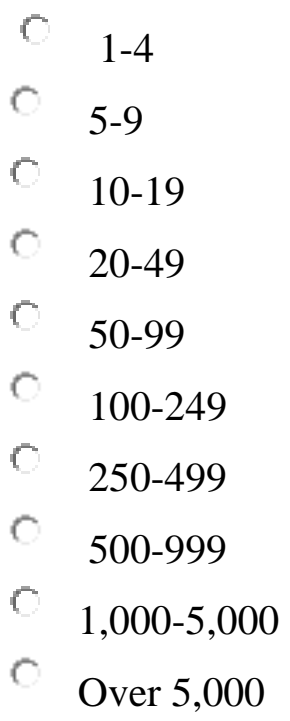

11. For how many new ventures have you been the founder and the principal manager so far?

$<$ Drop-down list $>$

12. Please indicate your organization's/firm's annual revenue: (last three years' average)
Under $\$ 50,000$
○ $\$ 50,000$ to $\$ 100,000$
$\$ 100,000$ to $\$ 500,000$ 
C $\$ 500,000$ to $\$ 1$ Million

\$1 Million to $\$ 10$ Million

C $\$ 10$ Million to $\$ 50$ Million

C $\$ 50$ Million to $\$ 100$ Million

C $\$ 100$ Million to $\$ 500$ Million

C $\$ 500$ Million to $\$ 1$ Billion

Over $\$ 1$ Billion 
CURRICULUM VITAE

Alireza Aghaey

\section{EDUCATION}

University of Louisville

Louisville, $\mathrm{KY}$

Ph.D. in Entrepreneurship

2020

Dissertation Title: Differences in Opportunity Evaluation between Corporate and Independent Entrepreneurs

University of Economic Sciences

MBA with Distinction, Concentration: Strategy

Tehran, Iran

2014

Thesis Title: A General Model of Strategic Fit

Sharif University of Technology

Tehran, Iran

Bachelor of Science in Electrical Engineering

2007

\section{REFEREED PUBLICATIONS}

Garrett, R.P., Mattingly, S., Hornsby, J., \& Aghaey, A. (2020) Impact of Relatedness, Uncertainty, and Slack on Corporate Entrepreneurship Decisions. Management Decision (DOI: 10.1108/MD-10-2019-1392)

\section{WORKING PAPERS}

Aghaey, A. The Effect of Banking Deregulations on the Decision of Private, Innovative Firms to Go Public. Targeted at: Journal of Entrepreneurship and Public Policy

Bullock, K.M., Aghaey, A., \& Fiet, J. O. Knowledge Sharing and Unlearning as Antecedents to Innovation in Small Firms. Targeted at: Journal of Small Business Management 


\section{TEACHING EXPERIENCE}

\section{Instructor}

Entrepreneurial Creativity and Innovation, University of Louisville

Spring 2018

Entrepreneurial Creativity and Innovation, University of Louisville

Fall 2018

Entrepreneurial Creativity and Innovation, University of Louisville

Spring 2019

New Venture Marketing, University of Louisville

Fall 2019

New Venture Marketing, University of Louisville

Spring 2020

\section{WORKSHOPS AND TRAININGS}

IRCA-certified QMS Auditor Certificate

TUV Rheinland AG

Technology Transfer Workshop Pardis Technology Park, Iran

Business Plan Writing Workshop

Pardis Technology Park, Iran

\section{PROFESSIONAL MEMBERSHIP}

Academy of Management (AOM)

Iranian Academy of Management Science (IAMS)

\section{RESEARCH PROJECTS}

An EFQM-based Quality Management Model for high-tech start-ups

Technology Transfer in East-Asian Countries

Pre-Revolution and Post-Revolution Technology-Development Plans in Iran

Impediments to Tourism Industry in Iran

\section{PROFESSIONAL EXPERIENCE}

Jammoj Engineering Co. Ltd.

Technical Supervisor and Strategy Advisor

- Supervised implementation of projects

- Led product and service development and expansion activities

- Managed relationships with customers/clients

- Developed and communicated strategic plan of the firm
Tehran, Iran

$2007-2014$ 


\section{GRANTS, AWARDS, AND HONORS}

\section{University Fellowship}

School of Interdisciplinary and graduate studies, University of Louisville

\section{Doctoral Student Research Grant}

John H. Schnatter Center for Free Enterprise, University of Louisville, College of Business. Grant award: $\$ 10,000$

\section{ACADEMIC SERVICE}

\section{Ad Hoc Reviewer}

Entrepreneurship Theory \& Practice

\section{Ad Hoc Reviewer}

Journal of Small Business Strategy

\section{Ad Hoc Reviewer}

Academy of Management Meetings - Entrepreneurship Div. 